\title{
Blockchain technology in agri-food value chain management: A synthesis of applications, challenges and future research directions
}

\author{
Guoqing Zhao ${ }^{1}$, Shaofeng Liu ${ }^{1}$, Carmen Lopez ${ }^{2}$, Haiyan Lu$^{1}$, Sebastian Elgueta ${ }^{3}$, \\ Biljana Mileva Boshkoska ${ }^{4,5}$, Huilan Chen ${ }^{1}$ \\ \{guoqing.zhao; shaofeng.liu; haiyan.lu; huilan.chen\}@ plymouth.ac.uk ${ }^{1}$ \\ Business School, University of Plymouth, $\mathrm{UK}^{1}$ \\ c.lopez@brighton.ac.uk ${ }^{2}$ \\ Brighton Business School, University of Brighton, $\mathrm{UK}^{2}$ \\ sebastian.elgueta@inia.cl ${ }^{3}$ \\ Laboratory of Pesticide Residue and Environment, Instituto de Investigaciones Agropecuarias, \\ INIA La Platina, 11610, Chile $^{3}$ \\ biljana.mileva@fis.unm.si ${ }^{4}$ \\ Faculty of Information Studies in Novo mesto, Ljubljanska cesta $31 \mathrm{a}^{4}$ \\ SI-8000 Novo mesto, Slovenia ${ }^{4}$ \\ Jožef Stefan Institute, Jamova cesta $39^{5}$ \\ 1000 Ljubjana, Slovenia ${ }^{5}$ \\ Corresponding author: \\ Guoqing Zhao \\ Business School, University of Plymouth, UK \\ guoqing.zhao@plymouth.ac.uk
}

\begin{abstract}
Agri-food value chain is an area of significant importance because of providing sustainable, affordable, safety and sufficient food, feed, fibre and fuel to consumers, it is critical to ensure these value chains running smoothly and successfully by applying advanced internet technologies. However, nearly all of these technologies have been applied in the agri-food value chain are centralised that could result in a serious trust problem. Blockchain technology is a new digital technological approach underpinned by the Industry 4.0 to ensuring data integrity and preventing tampering and single point failure through offering fault-tolerance, immutability, trust, transparency and full traceability of the stored transaction records to all agri-food value chain partners. This paper used systematic literature network analysis to review the state-of-the-art blockchain technology including its recent advances, main applications in agri-food value chain and challenges from a holistic perspective. The findings suggest that blockchain technology together with advanced information and communication technology and internet of things have been adopted for the improvement of agri-food value chain management in four main aspects: traceability, information security, manufacturing and sustainable water management. Six challenges have been identified including storage capacity and scalability, privacy leakage, high cost and regulation problem, throughput and latency issue, and lack of skills. Based on the critical analysis of literature, research gaps and future research directions are proposed in this paper regarding the applications and challenges of blockchain technology in agri-food value chain management. This study makes contributions to the extant literature in the field of agri-food value chain management by discovering the potential of blockchain technology and its implications for agri-food value chain performance improvements such as food safety, food quality and food traceability.
\end{abstract}

Keywords: Blockchain technology, Systematic literature network analysis, Industry 4.0, Internet of Things (IoT), Agri-food value chain digitisation 


\section{Introduction}

The agri-food value chain is a complex system responsible for the circulation of agri-food products from the initial stage of production to the final stage of consumption. In the circulation process, value chain members play a critical role in meeting the consumers' demand for agri-food products and maintaining the quality and safety of products (Leng et al. 2018). Simultaneously, with the rapid development of internet technologies in the value chain area, a large number of emerging technologies such as advanced information and communication technology (ICT) and the Internet of Things (IoT) have been applied to the agri-food value chain (Tian. 2017). However, almost all the systems applied to the agri-food value chain are centralised, monopolistic, asymmetric and opaque, and may result in serious trust problem. Therefore, consumers' confidence towards food safety has been broken after a series of food safety risk incidents and scandals over the last decades (Tian. 2017), such as mad cow disease, horsemeat scandal (Boyaci et al. 2014), toxic milk powder, genetically modified food and trench oil (Xiao et al. 2012). Consequently, detailed information of agrifood products from farm to fork is increasingly requested by consumers. Furthermore, how to build fault-tolerance, immutability, trust, transparency and full traceability of agri-food value chain (Caro et al. 2018), regulations and customers' expectations towards food quality and food safety (Bumbudsanpharoke and Ko. 2015), the complexity of agri-food value chain (Kirwan et al. 2017), and the current applications of technologies and their potential issues/pitfalls (Mor et al. 2015) have attracted increasing attention from academics and practitioners.

A potential solution to alleviate the above issues and concerns is usage of blockchain technology, which is a new digital technological approach underpinned by the Industry 4.0 to ensuring data integrity and preventing tampering and any single point failure. Four special elements - decentralised, immutable, consensus, and democratic that are unique to blockchain networks that make the technology more attractive in promoting trust and transparency in the agri-food value chain fraught with errors, duplication and redundancies (Yiannas. 2018). Crosby et al. (2016) underlines that blockchain is essentially a distributed database system that records transactional data or other digital events that have been executed and shared among value chain participants. It enables agri-food value chain participants to establish a decentralized consensus on the sequence of events and the current status of the transaction (Drescher. 2017). Blockchain technology uses a combination of different technologies that have been applied in computer science such as public/private key cryptography, cryptographic hash functions and database technologies (Ge et al. 2017), which provides an innovative solution to achieve food traceability, transparency, safety and security (Tse et al. 2017). Two prominent benefits of blockchain technology are that it provides a permanent transaction records which are grouped into individual blocks and cannot be tampered with; and it can replace those traditional paper tracking systems and manual monitoring systems, so as to prevent the traditional way of the value chain from suffering the inaccurate impact (Faye. 2017).

The academic interest in investigating the application of blockchain technology in agri-food value chain management has been progressively expanded, with a rapid increase in the contributions of academic experts covering this aspect (Tian. 2016; Tse et al. 2017; Chen. 2018; Kamath. 2018). Moreover, blockchain technology used in the agri-food value chain seems to be a promising research stream for future research, especially in the era of Industry 4.0 (Lin et al. 2017; Xu et al. 2018). However, only a limited number of studies analyse the 
current applications and future research directions of blockchain technology in different industries. We found three reviews concerned with the blockchain technology and its impact on the social and economy, drawn up, respectively, by Anascavage and Davis (2018), who identified 16 areas that blockchain technology could be applied to, including food security; Tama et al. (2017) acknowledge four areas that blockchain technology has been applied to and considers that blockchain technology plays an important role in guaranteeing the traceability of the agri-food value chain; and finally Yli-Huumo et al. (2016) conducted a systematic literature review (SLR) on current research of blockchain technology including security, wasted resources, usability and privacy. These reviews are, however, relatively general, and given the current research and applications of blockchain technology, none of the reviews addresses the application of the blockchain technology in the agri-food value chain management. Therefore, there is a lack of up-to-date reviews that offer a comprehensive overview of the main issues related to current applications, challenges and future research directions of the blockchain technology in the agri-food value chain management.

Considering the above arguments, the main objective of this study is to fill this gap by offering a systematic literature network analysis (SLNA) of the recent contributions of blockchain technology in the agri-food value chain management, highlighting the research that has been developed over time, and identifying the challenges of applying blockchain technology to the agri-food value chain management, and proposing the most promising research directions for the future.

The remainder of this paper is organised as follows. The methodology adopted in this paper is described in Section 2, while the application of the research methodology to the context under study is provided in Section 3. Then, the current applications of blockchain technology in the agri-food value chain management are presented in Section 4 followed by the challenges for applying blockchain technology in the agri-food value chain that are presented in Section 5. The research gaps and proposed future research directions are presented in Section 6. Finally, conclusions and research limitations are drawn in Section 7.

\section{Research methodology: systematic literature network analysis}

Systematic literature network analysis (SLNA) is constituted with two methods: systematic literature review (SLR) and citation network analysis (CNA). The purpose of integrating these two existing methodologies (SLR and CNA) is to maximize the advantages related to each of them: SLR provides a reproducible and rigorous method that is applied in this study to select the most relevant and high-quality studies from previous literature of blockchain technology in agri-food value chain management. Through synthesising of the literatures, the state-of-the-art of applications and the challenges to apply blockchain technology in agri-food value chain management will be revealed. Simultaneously, why blockchain technology matters in agri-food value chain management is also disclosed. CNA offers an evidencebased approach to identifying the most-cited studies from the selected databases, revealing the contributions on blockchain technology theory building in the agri-food value chain management as well as suggesting future research directions that can facilitate the application of the blockchain technology to the agri-food value chain management (Colicchia and Strozzi. 2012). The process of SLNA from the combination of SLR and CNA is shown in Appendix A.

\section{Applying the SLNA to the area under study}


The process of how to apply SLNA to the area of blockchain technology in agri-food value chain management is described in the following five sub-sections.

\subsection{Formulating the research questions}

The first stage of conducting SLNA is to formulate research questions. It is important to have well-specified, informative and clearly formulated research questions to avoid bias, error and ambiguity (Hohenstein et al. 2015). Therefore, the research questions were formulated based on the following process: (1) Brainstorming all types of applications of blockchain technology that can be used in agri-food value chain management; (2) Consulting with three experts in academia and agri-food industry to evaluate whether it is possible to apply the blockchain technology in these areas; (3) Examining possible applications of blockchain technology that can be applied to the agri-food value chain management. Based on the above processes and principles, the following research questions were formulated:

$R Q 1$. What are the main applications of blockchain technology that have been developed in agri-food value chain management?

$R Q 2$. What are the key challenges for applying blockchain technology to agri-food value chain management?

$R Q 3$. What are the research gaps and future research directions for applying blockchain technology to agri-food value chain management?

\subsection{Locating study}

Denyer and Tranfield (2009) proposed that a comprehensive list of core contributions is necessary to answer the review questions by searching the most relevant and high-quality studies. Eight databases were selected for literature search, including ScienceDirect, Web of Science, Scopus, Taylor \& Francis Online, Wiley Online Library, Emerald, Google Scholar and IEEE Xplore. The rationale for selecting these databases is that they include the top science and technology journals, conference proceedings and business research journals.

Consistent with other SLR papers in blockchain technology (e.g. Gligor and Holcomb. 2012; Yli-Huumo et al. 2016; Melacini et al. 2018), the identified keywords were used as the search criteria in our review. Since the aim of this research is to identify the main issues relating to the applications of blockchain technology in agri-food value chain management, a combination of "blockchain" and "agri-food value chain management", with all the related terms were used for searching the title, keywords and abstract in the selected electronic academic databases. These keywords were combined later through Boolean connectors to constitute different search strings to be applied in the databases. Furthermore, consultation with various practitioners and academics in the relevant field was conducted to confirm whether search strings were also necessary. Finally, a total of 45 search strings were identified by the authors to be included in the search process. A full list of search strings is shown in Table 1.

Table 1 Search strings for databases search

\begin{tabular}{ll}
\hline Keywords & "blockchain", "information security", "information transparency", "agriculture", \\
& "agricultural", "agribusiness", "agriculture safety", "agriculture security", "agriculture \\
& traceability", "food safety", "food security", "food traceability", "food supply", "food \\
& $\begin{array}{l}\text { trade", "food value chain management", "agriculture value chain management", "agri- } \\
\text { food value chain management", "agricultural trade" }\end{array}$ \\
\hline Databases & ScienceDirect, Web of Science, Scopus, Taylor \& Francis Online, Wiley Online Library, \\
\hline
\end{tabular}


Emerald, Google Scholar, IEEE Xplore

("blockchain" OR "information security" OR " information transparency") AND

("agriculture" OR "agricultural" OR "agribusiness" OR "agriculture safety" OR

" agriculture security" OR "food safety" OR "food security" OR "food traceability" OR

Search strings

"food supply" OR "food trade" OR "agriculture traceability" OR "food value chain

management" OR "agriculture value chain management" OR "agri-food value chain

management" OR "agriculture trade")

\subsection{Study selection and evaluation}

As a very recent and new research area, as discussed earlier, the term of blockchain technology was first coined in 2008 (Tama et al. 2017). In fact, the idea of blockchain technology was hardly discussed before 2008. Therefore, we use the year 2008 as the starting point to search relevant publications. Further, to find more relevant and important studies to be included in the analysis, various reference types such as journal papers, conference papers and book chapters were included in the systematic review. Simultaneously, the identification of key articles and book chapters that provide background information on blockchain technology in agri-food value chain management were found from different sources, including colleagues working in the same field. The initial search with the specified keywords and open access in the selected eight databases from 2008 to 2018 resulted in a preliminary sample of 632 contributions.

Afterwards, each study was checked by three authors by carefully analysing the abstracts, introductions and conclusions to reduce any subjective bias and enhance validity. Moreover, relevant book chapters and other publications that were not covered by the databases were then identified through carefully searching the references used in the previous literature (e.g. Gligor and Holcomb. 2012; Yli-Huumo et al. 2016; Melacini et al. 2018). The review of the work of influential authors in the field of blockchain technology in agri-food value chain management was also carried out by the same three authors. A series of inclusion and exclusion criteria were applied to include/exclude papers (Table 2), which were built through a brainstorming session among these three authors. Studies that do not meet the inclusion criteria or duplicates or non-relevant studies were eliminated. As a result, 62 studies were finally selected.

Table 2 Criteria for inclusion or exclusion studies

\begin{tabular}{ll}
\hline \multicolumn{1}{c}{ Inclusion criteria } & \multicolumn{1}{c}{ Rationale } \\
\hline $\begin{array}{l}\text { Articles were published in peer-reviewed } \\
\text { journals, conference proceedings and book } \\
\text { chapters in English }\end{array}$ & $\begin{array}{l}\text { Peer-reviewed journals, conference papers and book } \\
\text { chapters are considered to have better quality than non- } \\
\text { peer-reviewed articles }\end{array}$ \\
\hline Articles were published between 2008 and 2018 & $\begin{array}{l}\text { The year 2008 was selected as the starting point as the } \\
\text { term blockchain was coined in 2008 (Tama et al. 2017) }\end{array}$ \\
\hline $\begin{array}{l}\text { The selected articles contain at least one keyword } \\
\text { in their title or abstract }\end{array}$ & $\begin{array}{l}\text { Abstract or title focusing on the applications of } \\
\text { blockchain technology was selected }\end{array}$ \\
\hline $\begin{array}{l}\text { Judge relevance by fully reading all remaining } \\
\text { abstract, introduction and conclusion }\end{array}$ & $\begin{array}{l}\text { The remaining abstract, introduction and conclusion } \\
\text { focusing on the applications of blockchain technology in } \\
\text { agri-food value chain were selected }\end{array}$ \\
\hline $\begin{array}{l}\text { Judge relevance by fully reading all remaining } \\
\text { articles }\end{array}$ & $\begin{array}{l}\text { Articles focusing on the applications of blockchain } \\
\text { technology in agri-food value chain were selected }\end{array}$ \\
\hline
\end{tabular}

All selected 62 studies were read entirely by the three authors independently. By crossreferencing all the citations and references and talking with experts in the experts from academia and the agri-food industry, nine additional studies were identified and added, resulting in a total of 71 academic peer-reviewed journal papers, conference papers and book 
chapters to be included in the analysis. The search and selection process is presented in Appendix B.

\subsection{Citation network analysis (CNA)}

CNA is an effective and efficient way to reveal the articles that represent the basis of the field and to identify which articles were used by many other authors for the development of their contributions (Colicchia and Strozzi. 2012). The citation data (author, title, year, cited reference, source, time cited etc.) were collected from the Web of Science Core collection. Then, the software Gephi was used to build a citation network among the selected studies. Gephi is the leading visualization and exploration software for all graphs and networks, which can be applied to six main areas such as exploratory data analysis, link analysis, social network analysis, biological network analysis, and poster creation (Bastian et al. 2009). The rationale for this choice is that Gephi can provide large information handling capacity, friendly graphical user interface and high-quality output formats (Ahmed. 2017). As shown in Figure 1, a network consisting of 71 nodes was constructed. It comprises 47 connected components and 24 isolated components.

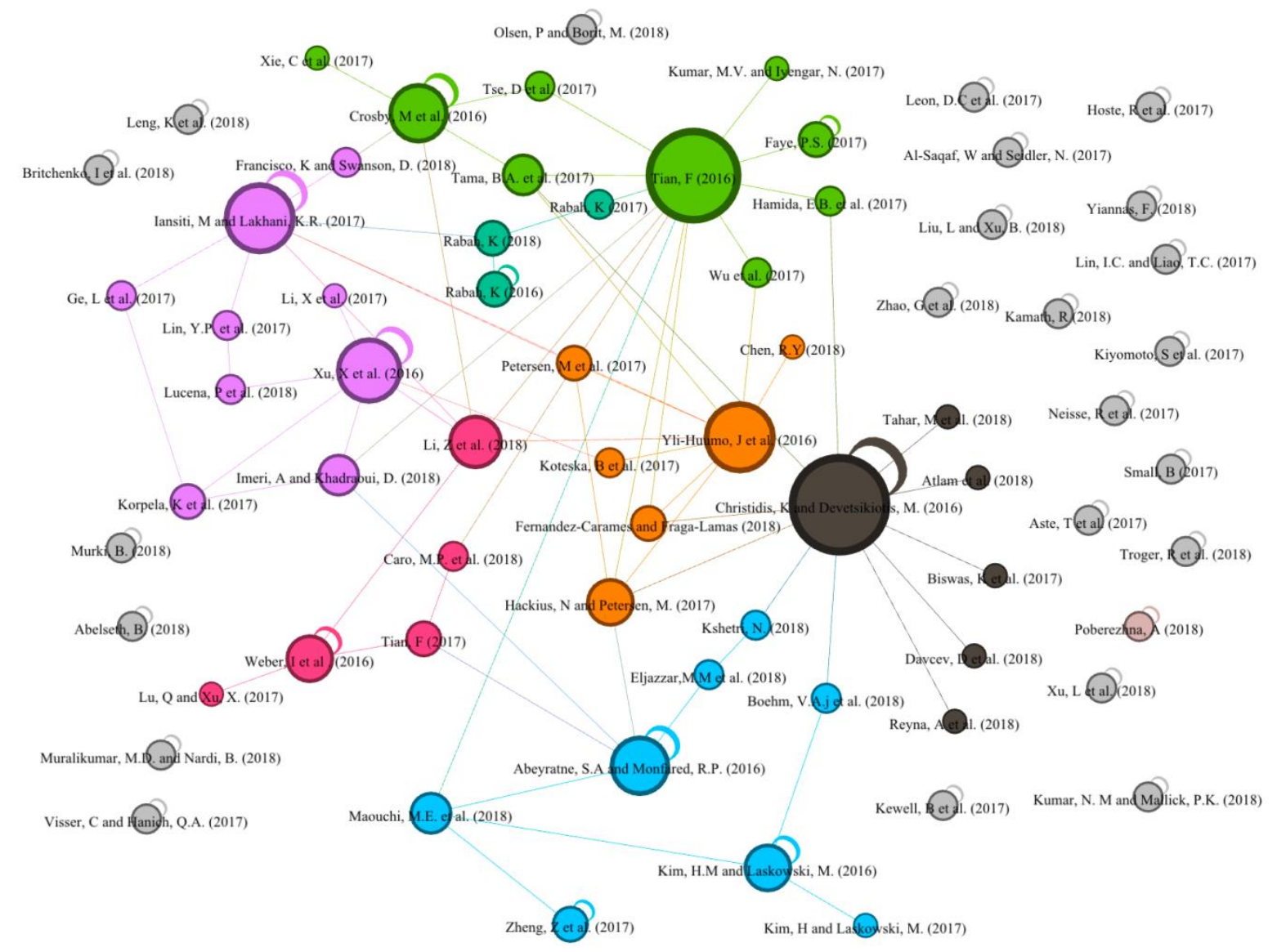

Figure 1 Citation network among the selected studies

Note: Node size depends on the quantity of connected components.

From the Figure 1, we can see that the connected components were divided into seven clusters according to their citation information. For example, the orange cluster summarized the opportunities that blockchain technology could be applied in agri-food value chain management such as blockchain combined with IoT to be used in agri-food value chain, as well as used in agri-food value chain traceability. It is important to note that most of the 
papers included in this cluster were literature review papers (Yli-Huumo et al. 2016; Koteska et al. 2017; Fernandez-Carames and Fraga-Lamas. 2018). A detailed analysis of benefits, opportunities and challenges of integrating blockchain technology with IoT were discussed in the cluster of black. There were four clusters (Light green, purple, red and blue) mainly discussed how to use blockchain technology to increase the agri-food value chain traceability and manufacturing conceptually and empirically. Simultaneously, different traceability models were proposed and tested. Finally, the green cluster represents how blockchain along with other technologies such as Big Data, Artificial Intelligence (AI) and Internet of Things served as an engine of the 4th industrial revolution, and how these technologies can revolutionize the current agri-food value chain management (Rabah. 2016; Rabah. 2017). The detailed information of each cluster is shown in Table 3.

Table 3 Detailed information of each cluster

\begin{tabular}{|c|c|c|}
\hline $\begin{array}{c}\text { Colour of } \\
\text { each cluster }\end{array}$ & Representative papers & $\begin{array}{c}\text { Main applications } \\
\text { discussed }\end{array}$ \\
\hline $\begin{array}{l}\text { Orange } \\
\text { cluster }\end{array}$ & $\begin{array}{l}\text { 1. Where is current research on blockchain technology? - A } \\
\text { systematic review (Yli-Huumo et al. 2016); } \\
\text { 2. Blockchain in logistics and supply chain: trick or treat? } \\
\text { (Hackius and Petersen. 2017); } \\
\text { 3. A review on the use of Blocckahin for the Internet of Things } \\
\text { (Fernandez-Carames and Fraga-Lamas. 2018); } \\
\text { 4. Blockchain implementation quality challenges: A literature } \\
\text { review (Koteska et al. 2017); }\end{array}$ & $\begin{array}{l}\text { Generally analyse the } \\
\text { current applications of } \\
\text { blockchain technology in } \\
\text { the value chain } \\
\text { management }\end{array}$ \\
\hline $\begin{array}{l}\text { Black } \\
\text { cluster }\end{array}$ & $\begin{array}{l}\text { 1. Blockchain and smart contracts for the internet of things } \\
\text { (Christidis and Devetsikiotis. 2016); } \\
\text { 2. Blockchain with Internet of Things: benefits, challenges and } \\
\text { future directions (Atlam et al. 2018); } \\
\text { 3. Blockchain-based distributed cloud/fog platform for IoT supply } \\
\text { chain management (Davcev et al. 2018); }\end{array}$ & $\begin{array}{l}\text { Discussed the } \\
\text { applications of } \\
\text { blockchain technology } \\
\text { integrated with IoT: } \\
\text { benefits, challenges and } \\
\text { future research directions }\end{array}$ \\
\hline $\begin{array}{l}\text { Light green } \\
\text { cluster }\end{array}$ & $\begin{array}{l}\text { 1. An agri-food supply chain traceability system for China based } \\
\text { on RFID \& blockchain technology (Tian. 2016); } \\
\text { 2. Use of blockchain technology in agribusiness: transparency and } \\
\text { monitoring in agricultural trade (Faye. 2017); } \\
\text { 3. A distributed ledger for supply chain physical distribution } \\
\text { visibility (Wu et al. 2017); }\end{array}$ & \multirow{2}{*}{$\begin{array}{l}\text { Proposed different } \\
\text { blockchain-based } \\
\text { traceability models that } \\
\text { could be used in agri- } \\
\text { food value chain } \\
\text { management }\end{array}$} \\
\hline $\begin{array}{l}\text { Purple } \\
\text { cluster }\end{array}$ & $\begin{array}{l}\text { 1. The truth about blockchain (Iansiti and Lakhani. 2017); } \\
\text { 2. The blockchain as a software connector (Xu et al. 2016); } \\
\text { 3. The security and traceability of shared information in the } \\
\text { process transportation of dangerous good (Imeri and Khadraoui. } \\
\text { 2018); }\end{array}$ & \\
\hline Red cluster & $\begin{array}{l}\text { 1. Untrusted business process monitoring and execution using } \\
\text { blockchain (Weber et al. 2016); } \\
\text { 2. Toward open manufacturing: A cross-enterprise knowledge and } \\
\text { services exchange framework based on blockchain and edge } \\
\text { computing (Li et al. 2018); } \\
\text { 3. A supply chain traceability system for food safety based on } \\
\text { HACCP, Blockchain \& Internet of Things (Tian. 2017); }\end{array}$ & \multirow{2}{*}{$\begin{array}{l}\text { Blockchain technology } \\
\text { was empirically } \\
\text { examined in the current } \\
\text { traceability system and } \\
\text { agri-food manufacturing }\end{array}$} \\
\hline Blue cluster & $\begin{array}{l}\text { 1. Blockchain ready manufacturing supply chain using distributed } \\
\text { ledger (Abeyratne and Monfared. 2016); } \\
\text { 2. Trade: A transparent, decentralized traceability system for the } \\
\text { supply chain (Maouchi et al. 2018); } \\
\text { 3. Holistic tracking of products on the blockchain using NFC and } \\
\text { verified users (Boehm et al. 2018); }\end{array}$ & \\
\hline $\begin{array}{l}\text { Green } \\
\text { cluster }\end{array}$ & $\begin{array}{l}\text { 1. Overview of blockchain as the engine of the 4th industrial } \\
\text { revolution (Rabah. 2016); } \\
\text { 2. Agricultural food supply chain powered by big data and } \\
\text { blockchain (Rabah. 2017); }\end{array}$ & $\begin{array}{l}\text { How blockchain } \\
\text { technology along with } \\
\text { other technologies such } \\
\text { as AI, IoT, Big Data }\end{array}$ \\
\hline
\end{tabular}




\begin{tabular}{|l|l|c|}
\hline & $\begin{array}{l}\text { 3. Convergence of AI, IoT, Big Data and Blockchain: A review } \\
\text { (Rabah. 2018); }\end{array}$ & $\begin{array}{c}\text { revolutionize the current } \\
\text { agri-food industry }\end{array}$ \\
\hline
\end{tabular}

As blockchain technology has gained increasing attention from researchers and practitioners, in 2016 Yli-Huumo et al. proposed an SLR on blockchain technology by highlighting current research topics, challenges and future research directions from a technological perspective. Their research results indicate four research gaps existing in the current study: (1) Lack of high-quality journal papers, most of the papers are published in conferences, symposiums and workshops; (2) The majority of current research is conducted in Bitcoin environment, rather than in other blockchain environments; (3) Lack of research on usability; (4) No research on the challenges for applying blockchain technology, such as latency, throughput and bandwidth.

Following Yli-Huumo et al. (2016), a series of research articles attempt to fill the research gaps. Tian (2016) and Faye (2017) have explored the field of blockchain technology in the context of the agri-food value chain from a traceability perspective. The issue addressed is how to embed blockchain technology in the current traceability system to increase the transparency and security of the agri-food value chain. With the evolution of research in the blockchain-based traceability system, some researchers tried to examine some generic models for facilitating the development of blockchain-based traceability system, such as the "TRADE" model proposed by Maouchi et al. (2018). Concerns about integrating blockchain technology in the agri-food value chain need to be addressed from a single company perspective firstly, therefore, Hamida et al. (2017) provided a detailed analysis on enterprise blockchains of its applications, challenges and opportunities. It is interesting to note that within these studies, the paper An agri-food supply chain traceability system for China based on RFID \& blockchain technology proposed by Tian (2016) is the most frequently cited paper, which has been cited 16 times by other authors among the selected papers (Table 4). At the current stage of research in blockchain technology for traceability, most researchers (e.g. Faye. 2017; Hamida et al. 2017; Tian. 2016) considered blockchain technology as a competitive advantage for agriculture value chain participants to gain trust from customers. Finally, most of these articles focus on addressing blockchain-based traceability system from the perspective of conceptual development.

Another stream of research examines how to combine blockchain technology with the IoT that can be applied in agri-food value chain management. Christidis and Devetsikiotis (2016) noted that the combination of blockchain technology with IoT would allow agri-food value chain participants to get automated time-consuming workflows in a new and unique way, as well as to reduce significant costs in the process. Following Christidis and Devetsikiotis (2016), many researchers have tried to contribute the theory-building of integrating blockchain technology with IoT from different perspectives. Hammi et al. (2018) explored how to improve trust relationship among agri-food value chain members by designing a blockchain-IoT application. Reyna et al. (2018) investigated how blockchain technology could potentially improve the IoT. Finally, Davcev et al. (2018) proposed a blockchain-based distributed cloud/fog platform for IoT to enable grape value chain. The research trends on blockchain-based IoT has been from generally discussing the challenges and opportunities for combining blockchain technology with IoT to how to design a blockchain-based IoT system for solving the trust issues among agri-food value chain members, which facilitate to build a distributed peer-to-peer systems to interact with agri-food value chain participants in a trust and auditable manner. 
Table 4 Most frequently cited articles in the citation network

\begin{tabular}{|c|c|c|c|c|c|c|}
\hline Rank & Title & $\begin{array}{l}\text { Author (s) and years } \\
\text { of publication }\end{array}$ & Source & Paper type & LCS & GCS \\
\hline $\mathbf{1}$ & $\begin{array}{l}\text { An agri-food supply chain traceability system for } \\
\text { China based on RFID \& blockchain technology }\end{array}$ & Tian (2016) & $\begin{array}{l}\text { 13th International Conference on Service } \\
\text { Systems and Service Management }\end{array}$ & $\begin{array}{l}\text { Conference } \\
\text { paper }\end{array}$ & 16 & 60 \\
\hline 2 & $\begin{array}{c}\text { Blockchain and smart contract for the Internet of } \\
\text { Things }\end{array}$ & $\begin{array}{c}\text { Christidis and } \\
\text { Devetsikiotis (2016) }\end{array}$ & IEEE Access & $\begin{array}{l}\text { Journal } \\
\text { paper }\end{array}$ & 12 & 350 \\
\hline 3 & $\begin{array}{l}\text { Where is current research on blockchain technology? - } \\
\text { A systematic review }\end{array}$ & $\begin{array}{l}\text { Yli-Huumo et al. } \\
\text { (2016) }\end{array}$ & PloS One & $\begin{array}{l}\text { Journal } \\
\text { paper }\end{array}$ & 8 & 157 \\
\hline 4 & The truth about blockchain & $\begin{array}{l}\text { Iansiti and Lakhani } \\
\text { (2017) }\end{array}$ & Harvard Business Review & $\begin{array}{c}\text { Journal } \\
\text { paper }\end{array}$ & 6 & 162 \\
\hline 5 & The blockchain as a software connector & Xu et al. (2016) & $\begin{array}{l}\text { 13th Working IEEE/IFIP Conference on } \\
\text { Software Architecture }\end{array}$ & $\begin{array}{l}\text { Conference } \\
\text { paper }\end{array}$ & 6 & 70 \\
\hline 6 & $\begin{array}{c}\text { Blockchain ready manufacturing supply chain using } \\
\text { distributed ledger }\end{array}$ & $\begin{array}{c}\text { Abeyratne and } \\
\text { Monfared (2016) }\end{array}$ & $\begin{array}{c}\text { International Journal of Research in Engineering } \\
\text { and Technology }\end{array}$ & $\begin{array}{l}\text { Journal } \\
\text { paper }\end{array}$ & 5 & 38 \\
\hline 7 & Blockchain in logistics and supply chain: trick or treat? & $\begin{array}{l}\text { Hackius and Petersen } \\
\text { (2017) }\end{array}$ & International Conference of Logistics & $\begin{array}{l}\text { Conference } \\
\text { paper }\end{array}$ & 5 & 8 \\
\hline 8 & $\begin{array}{l}\text { Toward open manufacturing: A cross-enterprise } \\
\text { knowledge and service exchange framework based on a } \\
\text { blockchain and edge computing }\end{array}$ & Li et al. (2018) & Industrial Management \& Data Systems & $\begin{array}{l}\text { Journal } \\
\text { paper }\end{array}$ & 5 & 4 \\
\hline 9 & Blockchain technology: beyond Bitcoin & Crosby et al. (2016) & Applied Innovation Review & $\begin{array}{l}\text { Journal } \\
\text { paper }\end{array}$ & 5 & 134 \\
\hline $\mathbf{1 0}$ & $\begin{array}{l}\text { Trade: A transparent, decentralized traceability system } \\
\text { for the supply chain }\end{array}$ & Maouchi et al. (2018) & $\begin{array}{c}\text { Proceedings of the 1st ERCIM Blockchain } \\
\text { Workshop } 2018\end{array}$ & $\begin{array}{l}\text { Conference } \\
\text { paper }\end{array}$ & 4 & 2 \\
\hline 11 & $\begin{array}{l}\text { A critical review of blockchain and its current } \\
\text { applications }\end{array}$ & Tama et al. (2017) & $\begin{array}{l}2017 \text { International Conference on Electrical } \\
\text { Engineering and Computer Science }\end{array}$ & $\begin{array}{l}\text { Conference } \\
\text { paper }\end{array}$ & 4 & 2 \\
\hline 12 & $\begin{array}{c}\text { Untrusted business process monitoring and execution } \\
\text { using blockchain }\end{array}$ & Weber et al. (2016) & Business Process Management & $\begin{array}{l}\text { Book } \\
\text { chapter }\end{array}$ & 3 & 74 \\
\hline 13 & $\begin{array}{c}\text { Convergence of AI, IoT, Big Data and Blockchain: A } \\
\text { review }\end{array}$ & Rabah (2018) & The Lake Institute Journal & $\begin{array}{l}\text { Journal } \\
\text { paper }\end{array}$ & 3 & 0 \\
\hline 14 & $\begin{array}{l}\text { A supply chain traceability system for food safety } \\
\text { based on HACCP, Blockchain \& Internet of Things }\end{array}$ & Tian (2017) & $\begin{array}{l}\text { 14th International Conference on Service } \\
\text { Systems and Service Management }\end{array}$ & $\begin{array}{l}\text { Conference } \\
\text { paper }\end{array}$ & 3 & 9 \\
\hline 15 & $\begin{array}{l}\text { Digital supply chain transformation toward blockchain } \\
\text { integration }\end{array}$ & Korpela et al. (2017) & $\begin{array}{l}\text { Proceedings of the 50th Hawaii International } \\
\text { Conference on System Sciences }\end{array}$ & $\begin{array}{l}\text { Conference } \\
\text { paper }\end{array}$ & 3 & 44 \\
\hline 16 & A survey on the security of blockchain systems & Li et al. (2017) & Future Generation Computer Systems & $\begin{array}{c}\text { Journal } \\
\text { paper }\end{array}$ & 3 & 25 \\
\hline
\end{tabular}

Notes: LCS = Local citation score shows the count of citations to a paper within the collection; GCS = Global citation score shows the total number of citations to a paper in the Web of Science. 
The trends towards stricter rules on food safety and food quality leads some researchers to explore potential applications of blockchain technology in other fields of agri-food value chain management, such as how to apply blockchain technology in food manufacturing (Abeyratne and Monfared. 2016) and how to use blockchain technology to increase the water sustainability (Poberezhna.2018).

Regarding the performance of applying blockchain technology in the agri-food value chain management, just a few papers measure the performance from the perspective of reducing tracking time to improve the traceability (Caro et al. 2018) and increasing the efficiency of the traceability in the agri-food value chain (Kamath. 2018). Simultaneously, several literature review papers investigated how blockchain technology has been applied in different industries such as agri-food industry, financial service and healthcare (Crosby et al. 2016; Tama et al. 2017). They provide insights on the development of blockchain technology in different industries and facilitate researchers to investigate how to transfer the knowledge from theory to practice.

\subsection{Thematic analysis}

Braun and Clarke (2006) stated that "thematic analysis is a method for identifying, analysing and reporting patterns (themes) within data, which provides core skills that will be useful for conducting many other forms of qualitative analysis". Holloway and Todres (2003) underlined that thematic analysis can be seen as a foundational approach for qualitative analysis. In this paper, thematic analysis was used to allow blockchain themes being generated by six phases of analysis: reading the whole paper collected from SLR, generating initial codes, searching for themes, reviewing themes, defining and naming themes, and finally presenting the results.

Following the process of thematic analysis, we divided the literature of blockchain technology in agri-food value chain management based on the following themes: (1) current applications of blockchain technology in agri-food value chain management; (2) the challenges for applying the blockchain technology in agri-food value chain management. The detailed results from thematic analysis are presented in Section 4. Tama et al. (2017) conducted a literature review on the blockchain technology and its current applications, where the majority of literature was concerned with the blockchain technology theory building and conceptual development. However, the findings in our study show that the trend has been gradually shifted from theory building trying to use blockchain technology in practice. Although the number of studies on how blockchain technology can be used in agrifood value chain management is increasing, there are a limited number of studies on how blockchain technology can be executed.

\section{Current applications of blockchain technology in agri-food value chain management}

The first application of the blockchain technology was Bitcoin - a peer-to-peer electronic cash system (Nakamoto. 2008). Then, blockchain technology evolved towards smart contracts with the ability to provide transparency and trust to the system (Christidis and Devetsikiotis. 2016). A smart contract is a kind of computer program that stores on the blockchain and executes by all consensus nodes in the network. It can translate contractual clauses into code and store them into the storage file, and operate them automatically and independently in a prescribed manner based on the data that was included in the triggering transaction (Szabo. 1994). Through operating the smart contracts, the need for trusted 
intermediaries between partners can be minimized and the occurrence of malicious or accidental exceptions can be reduced. Thus, blockchain technology has been generalized and applied in different domains such as finance (Hughes. 2018), smart city (Sharma and Park. 2018), healthcare (Cheng et al. 2018) and agri-food value chain (Abeyratne and Monfared. 2016). However, as reviewed by Yli-Huumo et al. (2016), more than $80 \%$ of the academic papers on blockchain technology focused on the Bitcoin system, while less than $20 \%$ deal with other blockchain applications. Although it is a relatively new technology, blockchain is rapidly advancing and developing. Lucena et al. (2018) stated that there was a huge opportunity for blockchain applications to global trade. Blockchain market is estimated to grow from 210.2 million USD to 2312.5 million USD in the period from 2016 to 2021 based on the Global Opportunity Report (2017). Due to its potential increase in the global market, it is expected that blockchain technology will play a critical role in facilitating future industry development and revolution. However, Poberezhna (2018) argued that the key challenge for blockchain was to be considered as a simply disruptive technology, rather than as an innovative integrative solution that could provide a value proposition across a number of business process. In the following four sub-sections, we analyse the literature of the applications of blockchain technology in agri-food value chain management by classifying them in four distinctive themes: traceability, information security, manufacturing and sustainable water management.

\subsection{Applying blockchain technology in agri-food value chain traceability}

According to Murki (2018), different value chains need to embed blockchain technology in the current traceability system to create more agile value chains and closer customer relationship. Tse et al. (2017) hold a similar view that the application of blockchain technology in the agri-food value chain may have been the optimal choice to fulfil the requirements of supervision and adaption of the fast-growing food market. More specifically, Kumar and Mallick (2018) construe that blockchain technology has wider applications in agri-food value chain such as food delivery and shipping data records, food online ordering and transaction data, and food quality assurance data. To integrate blockchain technology in the existing traceability system of agri-food value chain, many researchers have tried to explore the options from different perspectives. Tian (2016) proposed an agri-food value chain traceability system based on RFID (Radio-Frequency IDentification) and blockchain technology for helping Chinese agri-food markets to enhance their food safety and food quality during the logistics process. In their proposed traceability system, RFID was used for acquiring and sharing data in the agri-food value chain, meanwhile, blockchain technology was used for guaranteeing the data shared and published in this traceability system is reliable and authentic. However, some researchers argue that RFID technology and blockchain based traceability system has some defects in solving the counterfeit issues. For example, RFID tags can be cloned which can cause counterfeit parts to be circulated in the agri-food value chain (Bilal and Martin. 2013). To overcome the drawbacks of RFID, Boehm et al. (2018) proposed an updated traceability system using blockchain technology combined with Near Field Communication (NFC) and verified users. In their proposed traceability system, users must provide valid user credentials if they want to update a product's history on the 
blockchain. Thus, various changes of an agri-food product can be reported, and the capabilities of other members can be restricted at the same time. Therefore, holistic tracking agri-food products with higher transparency and security can be achieved. Faye (2017) underlined that the application of blockchain technology in agri-food industry would foster more transparency and thus customers' confidence towards agri-food products would be reestablished. Although blockchain technology has great potential for revolutionizing current agri-food value chain traceability systems, it still has some inherent defects such as scalability that needs to be tackled, especially when we face mass data in the real world. Recent innovations in blockchain, such as scaling would change this working manner that requires every computer in the blockchain to process every transaction (Gupta. 2017). Croman et al. (2016) argued that a scaled blockchain could accelerate the transaction process, without sacrificing high security, by determining the optimal number of computers to validate each transaction and divide work efficiently. Therefore, Tian (2017) investigated a value chain traceability system based on HACCP (Hazard Analysis and Critical Control Point), blockchain technology and IoT. In their proposed new decentralized traceability system, HACCP was used to prevent food risk occurrences, and IoT combined with blockchain technology was used to continuously deliver massive real-time food-related information to all value chain partners in an effective, safe and efficient manner. Then, a case testing experiment was used to check whether the system was feasible or not. The research results indicate that food safety, value chain efficiency and transparency have been effectively improved. Badzar (2016) emphasizes that openness and unchangeable attributes of blockchain ensure high transparency, stability and reliability of agri-food value chain, as well as provide liquidity, more accurate record-keeping and high transparency of ownership (Yermack. 2017). To have deep understanding of knowledge on how blockchain technology can be used to enhance agri-food business, Rabah (2017) conducted a review on the applications of big data and blockchain technology in the agri-food industry. Their research results reveal that blockchain technology played a critical role in creating secure and transparent ledger that was available to all the involved participants within the agri-food value chain including the producers, manufacturers, logistics service providers, wholesalers, retailers and regulators. They provide insights into the effects of blockchain technology on the current traceability system, and facilitate the development of blockchain technology in the agri-food value chain management. Finally, Biswas et al. (2017) propose a blockchain based wine value chain traceability system where every transaction is recorded as a block in the chain and is visible to relevant value chain members such as the grape grower, wine producer, bulk distributor, transit cellar, filler/packer, finished goods distributor, wholesaler and retailer entity. One of the most important features of their proposed system is that anyone can trace the purchase history of the wine by inputting the product ID in the system. However, their work just examines an example, rather than a practical application of blockchain technology in the wine value chain. Maouchi et al. (2018) argue that although various approaches have been proposed to create a decentralized traceability system for agri-food value chain, these works do not state the feasibility of their work and their application for the agri-food value chain. 
Due to the great potential benefits of applying blockchain technology to agri-food value chain traceability system, several agricultural industry enterprises around the world have evaluated the effect of blockchain technology. For example, Walmart plans to invest $\$ 25$ million over five years from 2017 to establish one food safety collaboration centre in Beijing to build a completely new food traceability system with blockchain technology. Their mango blockchain solution pilots reduced the time for tracking mango origins from seven days to 2.2 seconds, thus, more transparency and greater efficiency have been achieved in Walmart's food value chain. Then, a pork value chain traceability system combined with barcode has been built based on the mango blockchain solutions (Kamath. 2018). Yiannas (2018) states that the biggest advantage of this system is that it allows any trusted users to verify the traceability and authenticity of the product at any point of the pork value chain. Despite the increasing emphasis on applying blockchain technology in agri-food value chain traceability system, recent studies conducted by Kshetri (2018) show that just a few researchers have begun to systematically assess the effects of blockchain technology on current agri-food value chain traceability system. Caro et al. (2018) introduced an AgriBlockIoT traceability system for agri-food value chain management. It was constituted with three main components, a REST Application Interface with the responsibilities to integrate with the existing software system, a controller equipped with the abilities to query and convert the data records stored in the blockchain, and blockchain involved with smart contracts as a gateway to the blockchain itself. It is important to note that smart contracts can fire autonomously; hence creating records whenever anomalies are detected. Then, two different implementations, namely Ethereum and Hyperledger Sawtooth were used to do the performance analysis of traceability. Their research results indicate that Hyperledger Sawtooth has better performances than the Ethereum counterpart and may be more suitable for IoT devices, because Etherum is quite CPU-intensive. Based on the case study for grain quality assurance tracking, Lucena (2018) finds out that quality measurement throughout the transportation for grains along the value chain is always accompanied with fraud, poor monitoring and delay to final destinations. Their findings indicate that using blockchain technology in the grain value chain traceability system is the best way at present to reduce disputes among business partners and information asymmetries. Finally, Kumar and Iyengar (2017) demonstrated a blockchain based traceability framework for rice value chain management. In their proposed framework, blockchain was used to record all related issues happening within the rice value chain and monitor the security and quality of rice in the transportation process. It is important to note that all members in the rice value chain should register themselves and match their unique identities and digital profiles in the blockchain system. The research result indicates that the security of rice in the transportation process and the efficiency of the rice value chain have been greatly improved.

\subsection{Applying blockchain technology in the agri-food value chain information security}

Under the background of Industry 4.0 and distributed computing, the characteristics of information system in agri-food industry have experienced substantial changes. Blockchain technology has inherent benefits such as recording transactions in real-time, no intermediary, immutability and distributed ledger, which becomes the first choice for agri-food value chain 
managers to enhance information security (Murki. 2018). Tse et al. (2017) construed that blockchain was a well worthy technology for helping agri-food value chain participants to record and transfer transactions authentically. Leng et al. (2018) proposed a public blockchain for agricultural value chain system along with double-chain architecture. The research results reveal that the proposed agricultural business resource blockchain not only can increase the security of transaction information and privacy of enterprise information, but also can enhance the credibility of the public service platform and facilitate overall increase of efficiency across the whole value chain system. Neisse et al. (2017) explored a blockchainbased approach to achieve data accountability and provenance tracking. Their findings indicate that for the dynamic data frequently shared among value chain members such as the transaction record in agri-food value chain, which have strict scalability and performance requirements, controllers or processors should manage a contract that registers all subjects accepting all or part of usage conditions.

Recently, with the advancement of IoT, machine-to-machine (M2M) connections is estimated to increase to 3.9 billion to 2022 (Cisco. 2019). More and more agri-food value chain participants are being equipped with interconnected electronic devices and protocol suites to increase the connectivity and sophisticated data gathering and analytics capabilities (Reyna et al. 2018). However, most of the IoT solutions dependent on the centralized server-client paradigm, connecting to the cloud servers through the Internet (Fernandez-Carames and Fraga-Lamas. 2018). Decentralised architectures such as building a large Peer-to-Peer (P2P) Wireless Sensor Network (WSN) may cause privacy and security issues to the users (Triantafillou. 2003). Thus, effective tools to ensure information security need to be supported by agri-food value chain participants to meet the requested security requirements. To achieve this goal, some researchers have tried to explore how to ensure information security from a blockchain-based IoT perspective. Hammi et al. (2018) proposed a public blockchain-based approach in which devices can communicate with each other in a completely secure and efficient way by creating a secure virtual zone. After a series of tests, the research results indicate that the blockchain-based system demonstrated high resilience towards attacks. Iansiti and Lakhani (2017) underlined that blockchain technology could provide secure, irreversible, distributed, transparent and accurate information sharing service. After conducting research on blockchain-based distributed cloud/fog platform for IoT, Davcev et al. (2018) proposed that holistically using these blockchain-based ICT technologies has a positive effect in increasing the quality of agri-food products.

\subsection{Applying blockchain technology in agri-food manufacturing}

In today's highly competitive and knowledge-based economy, managing massive amount of information and services is the basic requirement for successful food manufacturers. As the information and services are diversified, growing in an accelerating velocity, and highly complex, an increase number of food manufacturers have difficulties in acquiring and managing them alone. Wang et al. (2016) state that it is necessary for food manufacturers to work together and sustain their competitiveness. To address this issue, some researchers have started integrating blockchain concept into manufacturing practices. Li et al. (2018) proposed a decentralized framework to manage the knowledge and services shared between different 
enterprises based on the blockchain application involved smart contracts and edge computing. In their proposed framework, edge computing acted as a foundation for providing distributed network, storage and computing capabilities in the manufacturing environment. The smart contracts played as interfaces between enterprise and its partners for successfully interact. Thus, a signed secure and controllable connection between the enterprise and the partner could be built with the transaction record and the status were updated on the blockchain. A case study was used to examine the effectiveness of the decentralized framework. The case study results indicate that manufacturers can develop scalable and flexible businesses at a lower cost, and ultimately the overall quality, efficiency, and effectiveness of manufacturing services can be improved. Furthermore, Zhao et al. (2018) built a model of manufacturing service information based on blockchain principle and cloud computing, which theoretically solves the problems of sharing and securing the manufacturing resources, recalling the product data and guaranteeing the quality of the processing. Finally, Kumar and Mallic (2018) reported that blockchain technology could be used in various perspectives of manufacturing, such as manufacturing management, production data, product warranty information and product assurance. Although blockchain technology has been seen as a critical element in the manufacturing sector in recent years, the role of blockchain technology for promoting resilience, scalability, security and autonomy of manufacturing service has been relatively overlooked (Xu et al. 2018).

\subsection{Applying blockchain technology in sustainable water management}

The agriculture productivity is highly dependent on water resource management. How to use water resources effectively and efficiently is crucial for agriculture development. To drive the sustainable development of water, it is critical to address water scarcity aspects that are deeply interrelated with agri-food development. Therefore, Civic Ledger (2017) considered to develop a blockchain-enabled peer-to-peer trading platform (Water Ledger) that would allow more irrigators to participate in the platform that entitles and allocates water securely and transparently, further boosting the overall efficiency of water resources. Though creating new digital identity for irrigators and digitizing the water assets in agri-food value chain will cost a lot of money, Poberezhna (2018) argues that blockchain combined with smart contracts can potentially help water companies and government bodies to access real-time data regarding market shares, consumption patterns and management of utility bills of consumers, thus, greater transparency to regulators and auditors can be achieved. Their research also indicates that recordkeeping will be significantly reduced when the blockchain platform is applied in water trading.

\section{The challenges for applying blockchain technology in agri-food value chain}

Blockchain technology is still in testing phase and its implementation in agri-food value chain management has some issues that need to be tackled. Therefore, in this section, we will scrutinize the challenges to apply blockchain technology in agri-food value chain management. A review of the literature indicates that there are six main challenges for applying blockchain technology in agri-food value chain management: storage capacity and 
scalability issue, privacy leakage, regulation problem, high cost problem, throughput and latency issue, and lack of skills.

\subsection{Storage capacity and scalability}

Storage capacity along with scalability issues have been deeply questioned in the blockchain. Koteska et al. (2017) stated that one of the main challenges for blockchain implementation is scalability. To provide theoretically proven security, it is necessary to have a large number of full nodes (a node that can fully validate transactions and blocks) in the blockchain implementation. The nodes in the blockchain network are expected to validate each transaction of each block (Reyna et al. 2018). Otherwise, blockchain implementation in agrifood value chain management might result in a less decentralized system. Koteska et al. (2017) proposed that scalability negatively affected three dimensions of the blockchain, the size of the data on the blockchain, the transaction processing rate and the latency of data transmission on the blockchain.

Although only full nodes store the full chain, storage requirements are also significant (Reyna et al. 2018). For example of the Bitcoin, the blockchain is always growing with a rate of $1 \mathrm{MB}$ per block every ten minutes and store a large amount of data in every node that no interest for them (Fernandez-Carames and Fraga-Lamas. 2018). As the number of transactions increase in the agri-food value chains, the amount of data becomes larger, and the loading of store and computing accompanied with data becomes harder, which results in the blockchain becoming bulky (Zheng et al. 2017). Simultaneously, every participant in the agri-food value chain needs to constantly store all transaction data to validate them on the blockchain because they need to check if the source of the current transaction is unspent or not (Lin and Liao. 2017). Thus, with the node size increasing, additional resources are required by the nodes. Finally the system's capacity scale is reduced and synchronization time for the new user is increased (Reyna et al. 2018).

\subsection{Privacy leakage}

In the blockchain, each transaction can be traced, checked and audited and every user can be identified by their public key or its hash. Undoubtedly, blockchain technology provides a new level of transparency and helps to build trust. However, it also has negative effect on protecting users' privacy (Reyna et al. 2018). Kosba et al. (2016) stated that blockchain could not guarantee the transactional privacy even with the permission management because the information on blockchain was available to all participants who belonged to the blockchain network. Lu and Xu (2017) underlined that every member could access all information on the blockchain because there were no privileged users. Maouchi et al. (2018) argued that some agri-food value chain members might be competitors with each other and they did not enjoy the transparent traceability system. Therefore, many efforts for protecting privacy in blockchain has been done such as obfuscation on the transaction relationships to prevent linking or tracing analysis, hiding the identifies of the sender and the receiver through complicated cryptographic schemes, and blinding the transaction content whilst retaining the verifiability and computability (Feng et al. 2019). In order to ensure transactions are not 
easily to be traced to any given person or computer, Monero (2019) applies ring of signatures scheme to guarantee transactions untraceable. Other schemes such as Stealth Addresses, Pedersen Commitments, Ring Signature, Homomorphic Encryption, Zero-knowledge-proof have been used in blockchains to improve privacy, but no schemes can hide the sender, the receiver and the amount at the same time (Hamida et al. 2017). Kosba et al. (2016) tackled these privacy issues differently through using encrypted transactions. The Hawk - a decentralized smart contract is responsible for translating the generic code written by programmers into cryptographic primitives such as zero-knowledge proofs that retaining transactional privacy. After researching in the wine value chain traceability system, Biswas et al. (2017) stated that there were two drawbacks of the blockchain technology: one is the transaction speed; the other one is privacy as neither companies nor individuals would like to publish all information onto a public database.

\subsection{High cost problem}

Lin and Liao (2017) proposed that agri-food value chain participants would need a lot of money and time to embed blockchain technology in the current agri-food value chain traceability system. Yli-Huumo et al. (2016) noted that when blockchain became more complex, the computational power would be another critical issue, as it required more computational power to confirm more blocks. Simultaneously, energy consumption also needs to be taken into consideration (Faye. 2017). After conducting a case study on blockchain-based traceability system, Lu and Xu (2017) pointed out some public blockchains inherent with a proof-of-work consensus mechanism wasted a lot of electricity. Most of the electricity is consumed in two different ways: (1) a large amount of electricity is used for the mining process, which involves a consensus algorithm that consists in a sort of brute force search for a hash; (2) another amount of electricity is consumed in peer-to-peer communications because it requires an edge device to be powered (Fernandez-Carames and Fraga-Lamas. 2018).

\subsection{Regulation problem}

Agri-food value chains are extended across the globe. Hence, applying blockchain technology in agri-food value chain management needs to be considered from a global perspective. However, blockchain is a new technology that involves different people from various countries without any legal or regulation to follow. Additionally, the absence of a central authority and the non-existent of censorship in the current blockchain system, this situation creates many uncertainties (Reyna et al. 2018). Atlam et al. (2018) stated that this was a serious problem for both agri-food manufacturers and service providers. Therefore, it is necessary to introduce new laws or regulations to monitor and regulate blockchain applications in the agri-food industry for compliance (Crosby et al. 2016). After conducting a case study on grain quality assurance tracking-based on blockchain technology, Lucena et al. (2018) found a controversial issue when using blockchain technology regarding its legal value. Their research also indicates that complex agri-food value chain scenarios involving international trade and arbitration laws are yet to be proven. 


\subsection{Throughput and latency issue}

In the context of agri-food value chain management, due to the original restriction of block size and the time interval used to generate a new block, the current processing capacity of blokchain cannot fulfil the requirements of processing millions of transactions in real-time. Aste et al. (2017, p.26) stated that "a system that could handle large transaction volumes would require large blocks or mechanisms in which multiple blocks are validated simultaneously". All the above issues will cause a big problem for clients when running a blockchain-based system. After investigating an RFID and blockchain based traceability system for agri-food value chain, Tian (2016) stated that there were two obstacles for applying blockchain technology: (1) the transaction capacity of blockchain is restricted to seven transactions per second due to the restricted size of block; (2) how to deal with storage and synchronization issues with the growing size of the blockchain.

Regarding latency, it is critical to note that current blockchain system needs some time to process transactions. For example, in the case of Bitcoin, block creation times follow a Poisson distribution with an average of ten minutes (10-minute block interval with 6-block confirmation) (Fernandez-Carames and Fraga-Lamas. 2018). As for Ethereum, it is estimated around 3 minutes for 14-second block interval with 12-block confirmation ( $\mathrm{Xu}$ et al. 2017). Jindal et al. (2019) construed that the time required for generating blocks and validating transactions is increases with an increase in the number of transactions. Sharma et al. (2018) evaluated the performance of a blockchain-based distributed framework involved with Proofof-Work algorithm and found that additional cost in computing sources and more processing time is required in case of network delays.

\subsection{Lack of skills}

Given that blockchain is a new technology, a limited number of people have in-depth knowledge and skills about how blockchain can be used in agri-food value chain management (Atlam et al. 2018). To obtain general knowhow in blockchain technology and expectations of the technology in the context of agri-food value chain, Ge et al. (2017) conducted numerous interviews and meetings with agri-food value chain stakeholders. They found that a considerable level of scepticism existed among stakeholders with low know-how of blockchain technology, partly due to the way blockchain was portrayed as panacea to all information problems, partly due to a series of technical issues that remained to be resolved. Therefore, Iansiti and Lakhani (2017) proposed that applying blockchain technology in the agri-food value chain was likely to be a long process. Simultaneously, a widespread lack of understanding on how blockchain works in other areas also exists (Banafa. 2017).

\section{Discussion: research gaps and future research directions}

Below, we summarized the research gaps and future research directions on blockchain technology in agri-food value chain management based on our systematic review of the literature. 


\subsection{Future research directions for the applications of blockchain technology in agri-food value chain management}

The analysis of the applications of blockchain technology in agri-food value chain management allows us to better understand how blockchain technology has been applied and evolved in agri-food value chain management. Several directions for future research about implementing blockchain technology in agri-food value chain management are suggested and summarized in the following.

$>$ In the context of applying blockchain technology in agri-food value chain traceability, various researchers proposed different blockchain-based traceability system that involved different technologies such as RFID, IoT, NFC, cloud computing, and big data, as well took different agri-food value chain entities into consideration (see Table 5). It is interesting to note that the traceability system proposed by Davcev et al. (2018) could provide a comprehensive function for monitoring the land status, vegetable status, as well as to help to achieve the transparent and secure agri-food value chain. Therefore, should be implemented in reality. However, most of the proposed traceability systems are staying in conceptual phase and there is little empirical research to suggest which one is most applicable to the reality. Additionally, just few researchers considered third-party regulators/authority organizations in their proposed traceability framework. Therefore, one of the priorities for researching the blockchain-based traceability system is to conduct empirical research involving third-party regulators/authority organizations on different context of agri-food value chains to assess the performance of the blockchain-based traceability system. Thus, future studies can evaluate the proposed blockchain-based traceability framework effects from different perspectives, such as computation costs, transaction processing speed, storage capability, and the overall efficiency of agri-food value chains.

$>$ There are two main areas in the literature for using blockchain technology to improve agri-food value chain information security: one is using blockchain technology alone; the other one is using blockchain technology combined with other technologies such as IoT (see Table 6). Obviously, double blockchain architecture has it unique advantages such as efficiency, transparency and privacy can be achieved with more data can be stored in the blockchain. Key technical components such as decentralized storage, mining hardware, and consensus mechanisms are easily to be achieved. However, it needs more effective consensus mechanism to deal with large amount of nodes and resources that stored in public service platform. Therefore, future research should investigate which consensus algorithm is more effective compared with others (Proof-of-Work, Proof-of-Stake, etc) in the same context. IoT applications have its own drawbacks such as they generate large volume of data and require connectivity and power for long periods. Besides, there are other limitations in memory, computer capacity, networks and limited power supply. In order to alleviate above issues, one important future research direction is to decide where the interactions will take place when combining blockchain technology with IoT, for example, inside the IoT, or blockchain, or a hybrid approach involving blockahin and IoT. It will need to discuss the advantages and disadvantages of these blockchain-IoT based 
applications through comparative analysis. This area is open for future researchers to investigate the impact and relative importance, and identify which one is the optimal choice to enhance agri-food information security.

Another finding of this study is a new trend of focusing on blockchain technology to achieve a higher level of sharing knowledge and services among agri-food manufacturers. Current agri-food manufacturing ecosystem is changing from integrated and centralized systems to shared and distributed systems. Most of the proposed framework for achieving higher performance were based on the blockchain technology and cloud computing, which aimed to provide a secure, low energy consumption and high efficiency systems to agri-food manufacturers. However, it still has some drawbacks. For example, unstable data transmission, lack of uniformed technology standard and low internet speed, etc. Blockchain technology integrated with edge computing provide a new way to achieve a higher level knowledge sharing performance through developing a distributed, sharing, standardized, and secured framework. Key technological components such as communication protocol, decentralized storage, smart contracts, edge cloud are all needed to build this system. However, there are questions remaining about the combination of blockchain and edge computing in enhancing overall efficiency and effectiveness of agrifood manufacturers. Thus, future studies should apply the blokchain technology and edge computing in different agri-food manufacturers using empirical and analytical tools to assess its effect on agri-food manufacturing.

A new trend emerging in the literature is the application of blockchain technology in sustainable water management. A few studies discussed how to apply blockchain technology to enhance water sustainability. However, these studies just considered how to enhance water sustainability from irrigator's perspective and water company's perspective, rather than taking the whole agri-food value chain stakeholders into consideration. Therefore, future work should holistically consider how to use blockchain technology to enhance water sustainability from the whole agri-food value chain perspective. 
Table 5 Blockchain technology used for agri-food value chain traceability

\begin{tabular}{|c|c|c|c|c|c|}
\hline Paper & Authors & $\begin{array}{l}\text { Involved } \\
\text { technologies }\end{array}$ & Involved entities & Advantages & Disadvantages \\
\hline $\begin{array}{l}\text { An agri-food supply chain } \\
\text { traceability system for China } \\
\text { based on RFID \& Blockchain } \\
\text { technology }\end{array}$ & $\begin{array}{l}\text { Tian } \\
(2016)\end{array}$ & $\begin{array}{l}\text { RFID \& Blockchain } \\
\text { technology }\end{array}$ & $\begin{array}{l}\text { Plant, farm, warehouse } \\
\text { centre, transport vehicle, } \\
\text { sales market, and } \\
\text { government departments \& } \\
\text { third-party regulators }\end{array}$ & $\begin{array}{l}\text { (1) Benefit to tracking and traceability } \\
\text { management; } \\
\text { (2) Benefit to enhance the credibility of the } \\
\text { agri-food safety information; } \\
\text { (3) Benefit to fighting against fake products. }\end{array}$ & $\begin{array}{l}\text { (1) High cost for using RFID; } \\
\text { (2) Transaction capacity and storage } \\
\text { capacity of blockchain technology }\end{array}$ \\
\hline $\begin{array}{l}\text { A supply chain traceability } \\
\text { system for food safety based on } \\
\text { HACCP, Blockchain \& Internet } \\
\text { of Things }\end{array}$ & $\begin{array}{l}\text { Tian } \\
(2017)\end{array}$ & $\begin{array}{l}\text { IoT \& Blockchain } \\
\text { technology with } \\
\text { distributed } \\
\text { databases }\end{array}$ & $\begin{array}{l}\text { Farmer/Producer, processor, } \\
\text { wholesaler, retailer, } \\
\text { authority organizations }\end{array}$ & $\begin{array}{l}\text { (1) Can deliver real-time information to all } \\
\text { supply chain members; } \\
\text { (2) Improve the efficiency and transparency of } \\
\text { the food supply chain; } \\
\text { (3) Extremely reduce the risk of centralized } \\
\text { information systems. }\end{array}$ & (1) High cost for using RFID. \\
\hline $\begin{array}{l}\text { Blockchain based wine supply } \\
\text { chain traceability system }\end{array}$ & $\begin{array}{l}\text { Biswas } \\
\text { et al. } \\
(2017)\end{array}$ & $\begin{array}{l}\text { RFID \& Blockchain } \\
\text { technology }\end{array}$ & $\begin{array}{l}\text { Supplier, grape grower, } \\
\text { wine producer, filler/packer, } \\
\text { freight operator, finished } \\
\text { goods distributor, } \\
\text { wholesaler, retailer, and } \\
\text { consumer }\end{array}$ & $\begin{array}{l}\text { (1) The proposed traceability system enables } \\
\text { transparency, accountability, safety, and } \\
\text { security in the overall process from the grape to } \\
\text { the bottle. }\end{array}$ & $\begin{array}{l}\text { (1) Low transaction speed; } \\
\text { (2) Privacy issues; } \\
\text { (3) Current system only provides } \\
\text { limited command-line based } \\
\text { instructions to store information; } \\
\text { (4) Can only deal with public data. }\end{array}$ \\
\hline $\begin{array}{l}\text { Holistic tracking of products on } \\
\text { the blockchain using NFC and } \\
\text { verified users }\end{array}$ & $\begin{array}{l}\text { Boehm } \\
\text { et al. } \\
(2018)\end{array}$ & $\begin{array}{l}\text { NFC \& Blockchain } \\
\text { technology }\end{array}$ & $\begin{array}{l}\text { Carrier, authority, service } \\
\text { provider, and consumer }\end{array}$ & $\begin{array}{l}\text { (1) Do not need to share a private key to sign a } \\
\text { transaction, assures confidentially of personal } \\
\text { information. }\end{array}$ & $\begin{array}{l}\text { (1) The effectiveness the system relies } \\
\text { on the correctness of the updates that } \\
\text { people perform; } \\
\text { (2) Additional overhead and costs. }\end{array}$ \\
\hline $\begin{array}{l}\text { Blockchain-based traceability } \\
\text { in agri-food supply chain } \\
\text { management: A practical } \\
\text { implementation }\end{array}$ & $\begin{array}{l}\text { Caro et } \\
\text { al. } \\
(2018)\end{array}$ & $\begin{array}{l}\text { IoT sensor devices } \\
\text { \& Blockchain } \\
\text { technology }\end{array}$ & $\begin{array}{l}\text { Provider of raw materials, } \\
\text { producer, processor, } \\
\text { distributor, retailer, and } \\
\text { consumer }\end{array}$ & $\begin{array}{l}\text { (1) Creating transparent, fault-tolerance, } \\
\text { immutable and auditable records for the } \\
\text { traceability system. }\end{array}$ & $\begin{array}{l}\text { (1) Quite CPU-intensive; } \\
\text { (2) Can only be using one language } \\
\text { when implementing logic. }\end{array}$ \\
\hline $\begin{array}{l}\text { Blockchain based distributed } \\
\text { cloud fog platform for IoT } \\
\text { supply chain management }\end{array}$ & $\begin{array}{l}\text { Davcev } \\
\text { et al. } \\
(2018)\end{array}$ & $\begin{array}{l}\text { IoT, Cloud } \\
\text { computing, RFID, } \\
\text { Big data \& } \\
\text { Blockchain } \\
\text { technology }\end{array}$ & $\begin{array}{l}\text { Farm, processor, transport } \\
\text { and packaging, wholesaler, } \\
\text { retailer, and consumer }\end{array}$ & $\begin{array}{l}\text { (1) Transparent and secure supply chain system } \\
\text { can be achieved; } \\
\text { (2) Real-time information on the air } \\
\text { temperature, air humidity and leaf wetness and } \\
\text { soil moisture; } \\
\text { (3) Lower power consumption. }\end{array}$ & $\begin{array}{l}\text { (1) High cost for applying these } \\
\text { technologies together. } \\
\text { (2) Requiring the devices to be powered } \\
\text { continuously, which could lead to waste } \\
\text { energy. }\end{array}$ \\
\hline $\begin{array}{l}\text { A case study for grain quality } \\
\text { assurance tracking based on a } \\
\text { blockchain business network }\end{array}$ & $\begin{array}{l}\text { Lucena } \\
\text { et al. } \\
(2018)\end{array}$ & $\begin{array}{l}\text { IoT \& Blockchain } \\
\text { smart contracts }\end{array}$ & $\begin{array}{l}\text { Farmer, rural credit bank, } \\
\text { private warehouse agent, } \\
\text { trading company agent, } \\
\text { food processing company }\end{array}$ & $\begin{array}{l}\text { (1) All the members in the agri-food supply } \\
\text { chain can share the same business rules and } \\
\text { transaction data, transaction transparency were } \\
\text { improved. }\end{array}$ & $\begin{array}{l}\text { (1) May have regulation problem if } \\
\text { involved in the international trade. }\end{array}$ \\
\hline
\end{tabular}


Table 6 Blockchain technology used for agri-food value chain information security

\begin{tabular}{|c|c|c|c|c|}
\hline Authors & $\begin{array}{c}\text { Involved } \\
\text { technologies }\end{array}$ & Architecture & Advantages & Disadvantages \\
\hline $\begin{array}{l}\text { Leng et al. } \\
\text { (2018) }\end{array}$ & \multirow[t]{2}{*}{ Blockchain } & $\begin{array}{l}\text { Double chain } \\
\text { architecture } \\
\text { based on public } \\
\text { service platform }\end{array}$ & $\begin{array}{l}\text { (1) Improve the transparency and } \\
\text { security of transaction information; } \\
\text { (2) Protect the privacy of enterprise } \\
\text { information; } \\
\text { (3) Increase the efficiency of the } \\
\text { system. }\end{array}$ & $\begin{array}{l}\text { (1) Slowly speed and } \\
\text { efficiency of consensus } \\
\text { algorithm }\end{array}$ \\
\hline $\begin{array}{l}\text { Neisse et } \\
\text { al. }(2017)\end{array}$ & & $\begin{array}{c}\text { Sole chain } \\
\text { architecture } \\
\text { based on public } \\
\text { service platform }\end{array}$ & $\begin{array}{l}\text { (1) Data privacy can be achieved; } \\
\text { (2) Immutable. }\end{array}$ & $\begin{array}{l}\text { (1) Scalability issues } \\
\text { (2) High cost }\end{array}$ \\
\hline \multirow{3}{*}{$\begin{array}{l}\text { Reyna et } \\
\text { al. (2018) } \\
\text { Hammi et } \\
\text { al. (2018) }\end{array}$} & \multirow{3}{*}{$\begin{array}{l}\text { Blockchain- } \\
\text { IoT }\end{array}$} & IoT-IoT & $\begin{array}{l}\text { (1) Fast latency; } \\
\text { (2) Security when work offline; } \\
\text { (3) IoT devices can communicate with } \\
\text { each other; } \\
\text { (4) Part of data can stored in blockchain }\end{array}$ & $\begin{array}{l}\text { (1) Low security when } \\
\text { working online }\end{array}$ \\
\hline & & IoT-Blockchain & $\begin{array}{l}\text { (1) Immutable record of interactions; } \\
\text { (2) Increase the autonomy of IoT } \\
\text { devices; } \\
\text { (3) All the interactions can be traced }\end{array}$ & $\begin{array}{l}\text { (1) Data were stored in } \\
\text { blockchain, bandwidth and } \\
\text { data would be increased }\end{array}$ \\
\hline & & $\begin{array}{l}\text { Hybrid } \\
\text { approach }\end{array}$ & $\begin{array}{l}\text { (1) Part of the data are stored in the } \\
\text { blockchain, and the rest are direct } \\
\text { shared with other partners }\end{array}$ & $\begin{array}{l}\text { (1) High cost because } \\
\text { involved more devices }\end{array}$ \\
\hline
\end{tabular}

\subsection{Future research directions for addressing the challenges of applying blockchain technology in agri-food value chain management}

From our systematic literature review, six key challenges emerged for applying blockchain technology in agri-food value chain management, they are storage capacity and scalability, privacy leakage, high cost problem, regulation problem, throughput and latency issue, and lack of skills. Although a growing body of literature is available on discussing these challenges, a number of challenges still exist. The purpose of this section is to highlight the main challenges identified in the literature and propose future research directions for unsolved problems. The identified solutions for the challenges of blockchain technology in agri-food value chain management are summarised in Table 7.

One of key challenges for applying blockchain technology in agri-food value chain is the storage capacity. Although some researchers broadly investigated several methods that could enhance the storage capacity, for example, store part of the data on-chain and part of the data off-chain (Xu et al. 2017), build a multi-layers blockchain architecture with different purposes (Hamida et al. 2017), and develop a new algorithm involved deep learning concept (Chen. 2018) (see Table 7). It is easily to find that more computational power is required when implementing these solution methods. Therefore, future work should investigate how to appropriate solve the data storage problem without increasing the computational power. Specifically, integrating the deep learning concept or artificially intelligence concept with current algorithms such as ant colony algorithm to achieve computational power efficiency and systematically eliminate the irrelevance data of blockchain provide a new route for solving the storage problem. Furthermore, 
comparative analysis of implementing these possible solutions in the context of agri-food value chain should be conducted empirically and analytically.

$>$ Most of the researchers investigated how to solve privacy leakage issues from single blockchain architecture perspective, and have applied different schemes such as Stealth Addresses, Pedersen Commitments, Ring signature, Homomorphic encryption, ZeroKnowledge-Proof to protect privacy of users. Few researchers investigated how to protect privacy from a double blockchain architecture perspective, that is, one for public, one for agri-food value chain participants. Therefore, future work should investigate how to design and evaluate double chain structures for blockchain. Further, conduct experiments to check how to combine the above-listed data privacy schemes to maximum the performance of data privacy mechanisms.

$>$ As for the high cost problem, different consensus algorithms have been proposed by various authors such as Proof-of-Stake and delegated Proof-of-Stake algorithm. Though these two algorithms have various advantages such as reducing the computing time, less nodes will be involved in the block validation, etc. However, no one have conducted comparative analysis using these two algorithms in empirical study in the context of agrifood value chain. This area is open for future researchers to systematically investigate the impact and relative importance of different mechanisms using empirical and analytical tools.

$>$ As discussed earlier, blockchain is a new technology which neither has any legislations or regulations to follow, nor has a defined way of how to insert the implications arising from blockchain technology into a norm setting. Although the application of blockchain technology in agri-food value chain is currently still in its infancy, it can be expected that more initiatives will be taken by various agri-food organizations (Ge et al. 2017). Therefore, more work should be taken from theory and empirical perspectives to check the effects of blockchain technology on the agri-food value chain, especially to check its effect in the international agri-food trade, and then formulate corresponding standards based on the research results.

$>$ As for the throughput and latency issue, some researchers proposed different methods to solve this problem such as implementing Bitcoin-NG algorithm and increase the size of each block (Eyal et al. 2016; Yli-Huumo et al. 2016). However, both of methods are not perfect enough which will have side effects such as larger blocks make full nodes more expensive to operate, and the latency is limited by the propagation time of the network, etc. Therefore, how to choose appropriate algorithm and block size without side effects become very important in solving the throughput and latency issue of blockchain. It is necessary to holistically consider this problem with continually experiments and get an optimal solution.

$>$ Finally, concerned with the lack of skills, we did not find many publications that gave us clear answers on this challenge. Only Ge et al. (2017) proposed two learning objectives for solving the challenge of lacking skills: (1) learn general knowledge of blockchain technology; (2) identify how to benefit from blockchain technology. 
Table 7 The identified solutions for the challenges of blockchain technology in agri-food value chain management

\begin{tabular}{|c|c|c|c|c|}
\hline Main challenges & Possible solutions & Advantages & Disadvantages & Future research directions \\
\hline \multirow{3}{*}{$\begin{array}{l}\text { Storage capacity } \\
\text { and scalability }\end{array}$} & $\begin{array}{l}\text { To store raw data off-chain, and to store } \\
\text { meta-data, small critical data, and hashes of } \\
\text { the raw data only on-chain (Xu et al. 2017) }\end{array}$ & $\begin{array}{l}\text { 1. Cost efficiency, better performance and } \\
\text { improved flexibility. }\end{array}$ & $\begin{array}{l}\text { 1. More computation power is required; } \\
\text { 2. How to integrate the on-chain data and } \\
\text { off-chain data is a problem. }\end{array}$ & \multirow{3}{*}{$\begin{array}{l}\text { 1. Comparative analysis of } \\
\text { different data storage methods } \\
\text { empirically; } \\
\text { 2. Integrating deep learning } \\
\text { concept or artificial intelligence } \\
\text { concept with current } \\
\text { algorithms. }\end{array}$} \\
\hline & $\begin{array}{l}\text { Removing old transactions, fragmenting the } \\
\text { global ledger into smaller sub-ledgers and } \\
\text { using a hierarchy of blockchains (Hamida et } \\
\text { al. 2017) }\end{array}$ & $\begin{array}{l}\text { 1. Reducing the cost because the data are } \\
\text { stored in different layer of blockchain; } \\
\text { 2. Improved the security of the system. }\end{array}$ & $\begin{array}{l}\text { 1. Transaction and validation speed will be } \\
\text { influenced with more data are stored in the } \\
\text { blockchain. } \\
\text { 2. More computation power is required. }\end{array}$ & \\
\hline & $\begin{array}{l}\text { Novel approach Takagi-Sugeno Fuzzy } \\
\text { cognitive maps ANN (Chen. 2018) }\end{array}$ & $\begin{array}{l}\text { 1. Eliminate of irrelevance data within } \\
\text { mining process. }\end{array}$ & $\begin{array}{l}\text { 1. More computation power is required; } \\
\text { 2. High cost problem. }\end{array}$ & \\
\hline \multirow[t]{2}{*}{ Privacy leakage } & Double Chain architecture (Leng et al. 2018) & $\begin{array}{l}\text { 1. Can guarantee the authenticity, integrity, } \\
\text { and non-tampering of transaction data, and } \\
\text { ensure the privacy of user information. } \\
\text { 2. Improve the throughput rate and } \\
\text { consensus speed of the system; } \\
\text { 3. Business extension can be implemented. }\end{array}$ & $\begin{array}{l}\text { 1. The consensus of public blockchain is } \\
\text { low. }\end{array}$ & \multirow{2}{*}{$\begin{array}{l}\text { 1. Conduct more empirical } \\
\text { studies on the performance of } \\
\text { the agri-food value chain with } \\
\text { double chain architecture; } \\
\text { 2. Conduct experiments to } \\
\text { check how to combine these } \\
\text { data privacy schemes to } \\
\text { maximum the performance. }\end{array}$} \\
\hline & $\begin{array}{l}\text { Stealth Addresses, Pedersen Commitments, } \\
\text { Ring signature, Homomorphic encryption, } \\
\text { Zero-Knowledge-Proof (Hamida et al. 2017); }\end{array}$ & $\begin{array}{l}\text { 1. Desired level of privacy can be achieved } \\
\text { through implementing mixed techniques. }\end{array}$ & $\begin{array}{l}\text { 1. No scheme can hide the sender, the } \\
\text { receiver and the amount at the same time; } \\
\text { 2. More computation time is required. }\end{array}$ & \\
\hline \multirow[t]{2}{*}{$\begin{array}{l}\text { High cost } \\
\text { problem }\end{array}$} & $\begin{array}{l}\text { Perform Proof-of-Stake algorithm (Xu and } \\
\text { Lu. 2017) }\end{array}$ & $\begin{array}{l}\text { 1. Only require a small amount of } \\
\text { computing time and the ability to ensure the } \\
\text { normal operation of the blockchain; } \\
\text { 2. Latency is shorter. }\end{array}$ & $\begin{array}{l}\text { 1. The consensus speed is low; } \\
\text { 2. Node is accumulated even when the node } \\
\text { is not connected to the network in the stake } \\
\text { stage. }\end{array}$ & \multirow{2}{*}{$\begin{array}{l}\text { 1. Conduct comparative } \\
\text { analysis of these two algorithms } \\
\text { using empirical study in the } \\
\text { context of agri-food value } \\
\text { chain. }\end{array}$} \\
\hline & $\begin{array}{l}\text { Perform delegated Proof-of-Stake algorithm } \\
\text { (Zheng et al. 2017) }\end{array}$ & $\begin{array}{l}\text { 1. Less nodes involved in block validation; } \\
\text { 2. Block size and intervals can be adjusted } \\
\text { by delegates. }\end{array}$ & $\begin{array}{l}\text { 1. Transactions are performed faster; } \\
\text { 2. Dishonest delegates can cause financial } \\
\text { loss. }\end{array}$ & \\
\hline $\begin{array}{l}\text { Regulation } \\
\text { problem }\end{array}$ & $\begin{array}{l}\text { 1. Design and implementation of a clear } \\
\text { regulatory framework for blockchain } \\
\text { implementation in the agri-food domain and } \\
\text { develop the evidence for the added value of } \\
\text { the blockchain technology (Ge et al. 2017); } \\
\text { 2. Government should set up blockchain } \\
\text { infrastructure to support policy formulation } \\
\text { (Fernandez-Carames et al. 2018). }\end{array}$ & $\begin{array}{l}\text { 1. Accelerate the process of formulating } \\
\text { policies and regulations related to the } \\
\text { blockchain implementation. } \\
\text { 2. Make blockchain technology is easily } \\
\text { accepted by agri-food value chain } \\
\text { participants. }\end{array}$ & $\begin{array}{l}\text { 1. Government need to invest a lot of } \\
\text { money and human resources, and may not } \\
\text { get the suitable results. }\end{array}$ & $\begin{array}{l}\text { 1. Investigate the effects of } \\
\text { blockchain technology on agri- } \\
\text { food value chain, especially on } \\
\text { the international agri-food } \\
\text { trade, and then formulate } \\
\text { standards and regulations. }\end{array}$ \\
\hline $\begin{array}{l}\text { Throughput and } \\
\text { latency issue }\end{array}$ & $\begin{array}{l}\text { 1. Implement Bitcoin-NG consensus } \\
\text { algorithm (Eyal et al. 2016); } \\
\text { 2. Increase the size of each block (Yli-Huumo } \\
\text { et al. 2016). }\end{array}$ & $\begin{array}{l}\text { 1. Improve the latency and bandwidth } \\
\text { without sacrificing other properties such as } \\
\text { security; } \\
\text { 2. More transactions speed per second. }\end{array}$ & $\begin{array}{l}\text { 1. Bandwidth is limited by the bandwidth of } \\
\text { nodes and the latency limited by the } \\
\text { propagation time of the network. } \\
\text { 2. More expensive for managing larger } \\
\text { blocks. }\end{array}$ & $\begin{array}{l}\text { 1. Holistically consider this } \\
\text { problem to find the optimal } \\
\text { solution for integrating Bitcoin- } \\
\text { NG consensus algorithm and } \\
\text { appropriate size of each block. }\end{array}$ \\
\hline Lack of skills & Not addressed & & & \\
\hline
\end{tabular}




\section{Conclusions}

In this study, we conducted an SLNA to review existing work on blockchain technology in agri-food value chain management. Through question formulation, locating studies, study selection and evaluation, we identified 71 publications, including journal papers, conference proceedings and book chapters. Then, we used software Gephi to build a citation network based on the citation data collected from Web of Science, which helped us to identify current trends and future research directions of blockchain technology in agri-food value chain management. The target publications of this study covered a broad spectrum of themes such as blockchain-based information security and traceability system, and blockchain-based water sustainability and food manufacturing.

By synthesising the literature of blockchain technology in agri-food value chain management within a 10-year timeframe (2008-2018), we discussed the evolution of blockchain technology and its application from different perspectives of agri-food value chain management. Then, we identified key challenges and proposed initial solutions for applying blockchain technology to agri-food value chain management. Furthermore, research gaps and future research directions were suggested for applying blockchain technology in agri-food value chain management. The findings of this study provide a solid foundation for future studies in the area of blockchain technology and agri-food value chain management.

Acknowledgment The work reported in this paper has benefited from the RUC-APS project funded by European Commission under the Horizon 2020 Programme (H2020-MSCA-RISE Award No. 691249).

\section{References:}

Abeyratne, S. A., Monfared, R. P. 2016. Blockchain ready manufacturing supply chain using distributed ledger. International Journal of Research in Engineering and Technology 5(9), pp. $1-10$.

Ahmed, K.H. 2017. A decision support framework for sustainable supply chain management. $\mathrm{PhD}$ Thesis, Loughborough University.

Anascavage, R and Davis, N. 2018. Blockchain technology: A literature review. Available at: https://papers.ssrn.com/sol3/papers.cfm?abstract_id=3173406 [Accessed: 3 July 2018].

Aste, T., Tasca, P., Matteo, T.D. 2017. Blockchain technologies: the foreseeable impact on society and industry. Computer 50(9), pp. 18-28.

Atlam, H.F., Alenezi, A., Alassafi, M.O., Wills, G.B. 2018. Blockchain with Internet of Things: benefits, challenges and future directions. International Journal of Intelligent Systems and Applications 10(6), pp. 40-48. 
Badzar, A. 2016. Blockchain for securing sustainable transport contracts and supply chain transparency - An explorative study of blockchain technology in logistics. Available at: https://lup.lub.lu.se/student-papers/search/publication/8880383 [Accessed: 8 August 2018].

Banafa, A. 2017. IoT and blockchain convergence: benefits and challenges. Available at: https://iot.ieee.org/newsletter/january-2017/iot-and-blockchain-convergence-benefits-andchallenges.html [Accessed: 15 August 2018].

Bastian, M., Heymann, S., Jacomy, M. 2009. Gephi: An open source software for exploring and manipulating networks. Available at: https://gephi.org/publications/gephi-bastianfeb09.pdf [Accessed: 05 September 2018].

Bilal, Z., Martin, K. 2013. A hierarchical anti-counterfeit mechanism: securing the supply chain using RFIDs. In: Danger, J-L., Debbabi, M., Msarion, J-Y., Garcia-Alfaro, J., Zincir Heywood, N eds. Foundations and Practice of Security. Cham: Springer.

Biswas, K., Muthukkumarasamy, V., Tan, W.L. 2017. Blockchain based wine supply chain traceability system. 2017 Future Technologies Conference. Vancouver, Canada, 29-30 November 2017. Vancouver: Canada.

Boehm, V.A.J., Kim, J., Won-Ki Hong, J. 2018. Holistic tracking of products on the blockchain using NFC and verified users. In: Kang, B.B.H and Kim, T eds. Information Security Applications. Cham: Springer.

Boyaci, I.H., Temiz, H.T., Uysal, R.S., Velioglu, H.M., Yadegari, R.J., Rishkan, M.M. 2014. A novel method for discrimination of beef and horsemeat using Raman spectroscopy. Food Chemistry 148, pp. 37-41.

Braun, V and Clarke, V. 2006. Using thematic analysis in psychology. Qualitative Research in Psychology 3(2), pp. 77-101.

Bumbudsanpharoke, N., Ko, S. 2015. Nano-food packaging: An overview of market, migration research, and safety regulations. Journal of Food Science 80(5), pp. 910-923.

Caro, M.P., Ali, M.S., Vecchio, M., Giaffreda, R. 2018. Blockchain-based traceability in agri-food supply chain management: A practical implementation. IoT Vertical and Topical Summit on Agriculture - Tuscany (IoT Tuscany). Tuscany, Italy, 8-9 May 2018. Rome: Italy.

Cheng, E.C., Le, Y., Zhou, J., Lu, Y. 2018. Healthcare services across China - on implementing an extensible universally unique patient identifier system. International Journal of Healthcare Management 11(3), pp. 210-216.

Chen, R-Y. 2018. A traceability chain algorithm for artificial neural networks using T-S fuzzy cognitive maps in blockchain. Future Generation Computer Systems 80, pp. 198-210.

Christidis, K., Devetsikiotis, M. 2016. Blockchain and smart contracts for the internet of things. IEEE Access 4, pp. 2292-2303. 
Cisco. 2019. Cisco visual networking index: global mobile data traffic forecast update, 20172022. Available at: https://www.cisco.com/c/en/us/solutions/collateral/service-provider/ visual-networking-index-vni/white-paper-c11-738429.html [Accessed: 20 March 2019].

Civic Ledger. 2017. Commercial trail: agricultural water trading rights [Online]. Available at: https://www.civicledger.com/civic/ [Accessed: 8 August 2018].

Colicchia, C., Strozzi, F. 2012. Supply chain risk management: a new methodology for a systematic literature review. Supply Chain Management: An International Journal 17(4), pp. 403-418.

Cook, D.J., Greengold, N.L., Ellrodt, A.G., Weingarten, S.R. 1997. The relation between systematic reviews and practice guidelines. Annals of Internet Medicine 127(3), pp. 210-216.

Croman, K., Decker, C., Eyal, I., Gencer, A.E., Juels, A., Kosba, A., Miller, A., Saxena, P., Shi, E., Sirer, E.G., Song, D., Wattenhofer, R. 2016. On scaling decentralized blockchains. 20th International Conference on Financial Cryptography and Data Security. Barbados, 2226 February 2016. Bridgetown: Barbados.

Crosby, M., Nachiappan., Pattanayak, P., Verma, S., Kalyanaraman, V. 2016. Blockchain technology: beyond bitcoin. Applied Innovation Review 2, pp. 6-19.

Davcev, D., Kocarev, L., Carbone, A., Stankovski, V., Mitreski, K. 2018. Blockchain-based distributed cloud/fog platform for IoT supply chain management. 8th International Conference on Advances in Computing, Electronics and Electronical Technology. Kuala Lumpur, Malaysia, 3-4 February 2018. Kuala Lumpur: Malaysia.

Denyer, D., Tranfield, T. 2009. The Sage Handbook of Organisational Research Methods. London: Sage.

DNV GL AS. 2017. Global Opportunity Report 2017 [Online]. Available at: https://www.globalopportunitynetwork.org/the-2017-global-opportunity-report.pdf [Accessed: 16 July 2018].

Drescher, D. 2017. Planning the Blockchain: The basic concepts of managing ownership with the blockchain. Blockchain Basics. Berkeley: Apress, pp. 57-62.

Durach, C.F., Wieland, A., Machuca, J.A.D. 2015. Antecedents and dimensions of supply chain robustness: a systematic literature review. International Journal of Physical Distribution \& Logistics Management 45(1/2), pp. 118-137.

Eyal, I., Gencer, A.E., Sirer, E.G., Van Renesse, R. 2016. Bitcoin-NG: A scalable blockchain protocol. Proceedings of the 13th USENIX Symposium on Networked Systems Design and Implementation. Santa Clara, USA, 16-18 March 2016. Washington: USA.

Faye, P.S. 2017. Use of blockchain technology in agribusiness: transparency and monitoring in agricultural trade. 13th International Conference on Service Systems and Service Management. Kuming, China, 24-26 June 2016. Beijing: China. 
Feng, Q., He, D., Zeadally, S., Khan, M.K., Kumar, N. 2019. A survey on privacy protection in blockchain system. Journal of Network and Computer Applications 126, pp. 45-58.

Fernandez-Carames, T.M., Fraga-Lamas, P. 2018. A review on the use of Blockchain for the Internet of Things. IEEE Access 6, pp. 2169-3536.

Ge, L., Brewster, C., Spek, J., Smeenk, A., Top, J. 2017. Blockchain for Agriculture and Food. Netherland: Wageningen Economic Research.

Gligor, D.M., Holcomb,M.C. 2012. Understanding the role of logistics capabilities in achieving supply chain agility: a systematic literature review. Supply Chain Management: An International Journal 17(4), pp. 438-453.

Gupta, V. 2017. A brief history of blockchain. Harvard Business Review. Available at: https://hbr.org/2017/02/a-brief-history-of-blockchain [Accessed: 09 August 2018].

Hackius, N., Petersen, M. 2017. Blockchain in logistics and supply chain: trick or treat? The Hamburg International Conference of Logistics. Hamburg, Germany, 12-13 October 2017. Berlin: Germany.

Hamida, E.B., Brousmiche, K.L., Levard, H., Thea, E. 2017. Blockchain for enterprise: overview, opportunities and challenges. The Thirteenth International Conference on Wireless and Mobile Communications. Nice, France, 23-27 July 2017. Paris: France.

Hammi, M.T., Hammi, B., Bellot, P., Serhrouchni, A. 2018. Bubbles of trust: a decentralized blockchain-based authentication system for IoT. Computers \& Security 78, pp. 126-142.

Hayouni, H., Hamdi, M. 2016. Secure data aggregation with homomorphic primitives in wireless sensor networks: A critical survey and open research issues. 13th International Conference on Networking, Sensing, and Control. Mexico City, Mexico, 28-30 April 2016. Mexico City: Mexico.

Hohenstein, N-O., Feisel, E., Hartmann, E. 2015. Research on the phenomenon of supply chain resilience: a systematic review and paths for further investigation. International Journal of Physical Distribution and Logistics Management 45(1/2), pp. 90-117.

Holloway, I., Todres, L. 2003. The status of method: flexibility, consistency and coherence. Qualitative Research 3, pp. 345-357.

Hoste, R., Suh, H., Kortstee, H. 2017. Smart farming in pig production and greenhouse horticulture: An inventory in Netherlands. Wageningen: Wageningen University \& Research.

Hughes, T.M. 2018. The global financial services industry and the blockchain. Journal of Structured Finance 23(4), pp. 36-40.

Hummon, N.P., Doreian, P. 1989. Connectivity in a citation network: the development of DNA theory. Social Networks 11(1), pp. 39-63. 
Iansiti, M., Lakhani, K.R. 2017. The truth about blockchain. Harvard Business Review 95(1), pp. 118-127.

Imeri, A., Khadraoui, D. 2018. The security and traceability of shared information in the process of transportation of dangerous goods. 9th IFIP International Conference on New Technologies, Mobility and Security. Paris, France, 26-28 February 2018. Paris, France.

Jindal, A., Aujla, G.S., Kumar, N. 2019. SURVIVOR: A blockchain based edge-as-a-service framework for secure energy trading in SDN-enabled vehicle-to-grid environment. Computer Networks 153, pp. 36-48.

Kamath, R. 2018. Food traceability on blockchain: Walmart's pork and mango pilots with IBM. The Journal of The British Blockchain Association 1(1), pp. 1-12.

Kirwan, J., Maye, D., Brunori, G. 2017. Acknowledging complexity in food supply chains when assessing their performance and sustainability. Journal of Rural Studies 52, pp. 21-32.

Korpela, K., Hallikas, J., Dahlberg, T. 2017. Digital supply chain transformation toward blockchain integration. Proceedings of the 50th Hawaii International Conference on System Sciences. Hawaii, USA, 4-7 January 2017. Washington: USA.

Kosba, A., Miller, A., Shi, E., Wen, Z., Papamanthou, C. 2016. The blockchain model of cryptography and privacy-preserving smart contracts. 2016 IEEE Symposium on Security and Privacy. San Jose, USA, 22-26 May 2016. Washington: USA.

Koteska, B., Karafiloski, E., Mishev, A. 2017. Blockchain implementation quality challenges: A literature review. 6th Workshop of Software Quality, Analysis, Monitoring, Improvement, and Applications. Belgrade, Serbia, 11-13 September 2017. Belgrade: Serbia.

Kshetri, N. 2018. Blockchain's roles in meeting key supply chain management objectives. International Journal of Information Management 39, pp. 80-89.

Kumar, M.V., Iyengar, N.Ch.S.N. 2017. A framework for blockchain technology in rice supply chain management. Advanced Science and Technology Letters 146, pp. 125-130.

Kumar, N.M., Mallick, P.K. 2018. Blockchain technology for security issues and challenges in IoT. Procedia Computer Science 132, pp. 1815-1823.

Leng, K., Bi, Y., Jing, L., Fu, H-C., Nieuwenhuyse, I.V. 2018. Research on agricultural supply chain system with double chain architecture based on blockchain technology. Future Generation Computer Systems 86, pp. 641-649.

Lin, I-C., Liao, T-Z. 2017. A survey of blockchain security issues and challenges. International Journal of Network Security 19(5), pp. 653-659.

Li, X., Jiang, P., Chen, T., Luo, X., Wen, Q. 2017. A survey on the security of blockchain systems. Future Generation Computer Systems. DOI: https://doi.org/10.1016/j.future.2017. 08.020 . 
Li, Z., Wang, W.M., Liu, G., Liu, L., He, J., Huang, G.Q. 2018. Toward open manufacturing: A cross-enterprise knowledge and services exchange framework based on blockchain and edge computing. Industrial Management \& Data Systems 118(1), pp. 303-320.

Lucena, P., Binotto, A.P.D., Silva Momo, F., Kim, H. 2018. A case study for grain quality assurance tracking based on blockchain business network. Proceedings of the Symposium on Foundations and Applications of Blockchain. Los Angeles, USA, 9 March 2018. Washington: USA.

Lu, Q., Xu, X. 2017. Adaptable blockchain-based systems: a case study for product traceability. IEEE Software 34(6), pp. 21-27.

Maouchi, M., Ersoy, O., Erkin, Z. 2018. Trade: A transparent, decentralized traceability system for the supply chain. Proceedings of 1st ERICM Blockchain Workshop 2018. Amsterdam, Netherlands, 8-9 May. Amsterdam: Netherlands.

Melacini, M., Perotti, S., Rasini, M., Tappia, E. 2018. E-fulfilment and distribution in omnichannel retailing: a systematic literature review. International Journal of Physical Distribution \& Logistics Management 48(4), pp. 391-414.

Monero. 2017. Available at: https://www.getmonero.org/ [Accessed: 15 March 2019].

Mor, R.S., Singh, S., Bhardwaj, A., Singh, LP. 2015. Technological implications of supply chain practices in agri-food sector - A review. International Journal of Supply and Operations Management 2(2), pp. 720-747.

Murki, B. 2018. Blockchain technology in supply chain management: A review. International Research Journal of Engineering and Technology 5(6), pp. 2497-2500.

Nakamoto, S. 2008. Bitcoin: A peer-to-peer electronic cash system. Available at: https://bitcoin.org/bitcoin.pdf [Accessed at: 16 July 2018].

Neisse, R., Steri, G., Nai-Fovino, I. 2017. A blockchain-based approach for data accountability and provenance tracking. Proceedings for Data Accountability and Provenance Tracking. Reggio Calabria, Italy, 29 August - 01 September 2017. Rome: Italy.

Poberezhna, A. 2018. Addressing water sustainability with blockchain technology and green finance. In: Marke, A. ed. Transforming Climate Finance and Green Investment with Blockchains. Cambridge: Academic Press, pp. 189-196.

Rabah, K. 2017. Agricultural food supply chain powered by big data and blockchain. Mara International Journal of Scientific \& Research Publications 1(1), pp. 55-64.

Rabah, K. 2018. Convergence of AI, IoT, Big Data and Blockchain: A review. The Lake Institute Journal 1(1), pp. 1-18.

Rabah, K. 2016. Overview of blockchain as the engine of the 4th industrial revolution. Mara Research Journal of Business and Management 1(1), pp. 125-135. 
Reyna, A., Martin, C., Chen, J., Soler, E., Diaz, M. 2018. On blockchain and its integration with IoT. challenges and opportunities. Future Generation Computer Systems 88, pp. 173190.

Sharma, P.K., Kumar, N., Park, J.H. 2018. Blockchain-based distributed framework for automotive industry in a smart city. IEEE Transactions on Industrial Informatics. DOI: 10.1109/TII.2018.2887101.

Sharma, P.K., Park, J.H. 2018. Blockchain based hybrid network architecture for the smart city. Future Generation Computer Systems - The International Journal of eScience 86, pp. 650-655.

Szabo, N. 1996. Smart contracts: building blocks for digital markets. Available at: http://www.fon.hum.uva.nl/rob/Courses/InformationInSpeech/CDROM/Literature/LOTwinte rschool2006/szabo.best.vwh.net/smart_contracts_2.html [Accessed: 14 March 2019].

Tama, B.A., Kweka, B.J, Park, Y., Rhee, K-H. 2017. A critical review of blockchain and its current applications. 2017 International Conference on Electrical Engineering and Computer Science. Palembang, Indonesia, 22-23 August 2017. Jakarta: Indonesia.

Tian, F. 2016. An agri-food supply chain traceability system for China based on RFID \& blockchain technology. 13th International Conference on Service Systems and Service Management. Kunming, China, 24-26 June 2016. Beijing: China.

Tian, F. 2017. A supply chain traceability system for food safety based on HACCP, Blockchain \& Internet of Things. 14th International Conference on Service Systems and Service Management. Dalian, China, 16-18 June 2017. Beijing: China.

Tranfield, D., Denyer, D., Smart, P. 2003. Towards a methodology for developing evidenceinformed management knowledge by means of systematic review. British Journal of Management 14(3), pp. 207-222.

Triantafillou, P., Ntarmos, N., Nikoletseas, S., Spirakis, P. 2003. NanoPeer networks and P2P worlds. Proceedings of the Third International Conference on Peer-to-Peer Computing. Linkoping, Sweden, 1-3 Sep 2003. Stockholm: Sweden.

Tse, D., Zhang, B., Yang, Y., Cheng, C., Mu, H. 2017. Blockchain application in food supply information security. IEEE International Conference on Industrial Engineering and Engineering Management (IEEM). 10-13 December 2017.

Wang, Z., Wang, Q., Zhao, X., Zhu, G. 2016. Interactive effects of external knowledge sources and internal resources on the innovation capability of Chinese manufacturers. Industrial Management \& Data Systems 116(8), pp. 1617-1635.

Weber, I., Xu, X., Riveret, R., Governatori, G., Ponomarev, A., Mendling, J. 2016. Untrusted business process monitoring and execution using blockchain. In: La Rosa M., Loos P., Paster O. (eds) Business Process Management. BPM 2016. Lecture Notes in Computer Science, vol 9850. Springer, Cham. 
Wu, H.Y., Li, Z.J., King, B., Miled, Z.B., Wassick, J., Tazelaar, J. 2017. A distributed ledger for supply chain physical distribution visibility. Information 8(4), pp. 137-155.

Xiao, J., Liu, Z.Y., Li, B.W. 2012. Research on a food supply chain traceability management system based on RFID. Journal of Agricultural Mechanization Research 34(2), pp. 181-184.

$\mathrm{Xu}, \mathrm{L} ., \mathrm{Xu}, \mathrm{E} ., \mathrm{Li}, \mathrm{L} .2018$. Industry 4.0: state of the art and future trends. International Journal of Production Research 56(8), pp. 2941-2962.

Xu, X., Pautasso, C., Zhu, L., Gramoli, V., Ponomarev, A., Tran, A.B., Chen, S. 2016. The blockchain as a software connector. 13th Working IEEE/IFIP Conference on Software Architecture. Venice, Italy, 5-6 April, 2016. Rome: Italy.

Xu, X., Weber, I., Staples, M., Zhu, L., Bosch, J., Bass, L., Pautasso, C., Rimba, P. 2017. A taxonomy of blockchain-based systems for architecture design. IEEE International Conference on Software Architecture. Gothenburg, Sweden, 3-7 April, 2017. Stockholm: Sweden.

Yermack, D. 2017. Corporate governance and blockchains. Review of Finance 21(1), pp. 731.

Yiannas, F. 2018. A new era of food transparency powered by blockchain. Innovations: Technology, Governance, Globalization 12(1-2), pp. 46-56.

Yli-Huumo, J., Ko, D., Choi, S., Park, S., Smolander, K. 2016. Where is current research on blockchain technology? - A systematic review. PLoS ONE 11(10), pp. 1-27.

Zhao, G., Zhang, G., Liu, M., Yu, S., Liu, Y., Zhang, X. 2018. Research on manufacturing service behaviour modelling based on block chain theory. AIP Conference Proceedings 1955, pp. 30-35.

Zheng, Z., Xie, S., Dai, H., Chen, X., Wang, H. 2017. An overview of blockchain technology: architecture, consensus, and future trends. 2017 IEEE International Congress on Big Data. Honolulu, USA, 25-30 June 2017. Washington, USA. 
Appendix A. The process of systematic literature network analysis

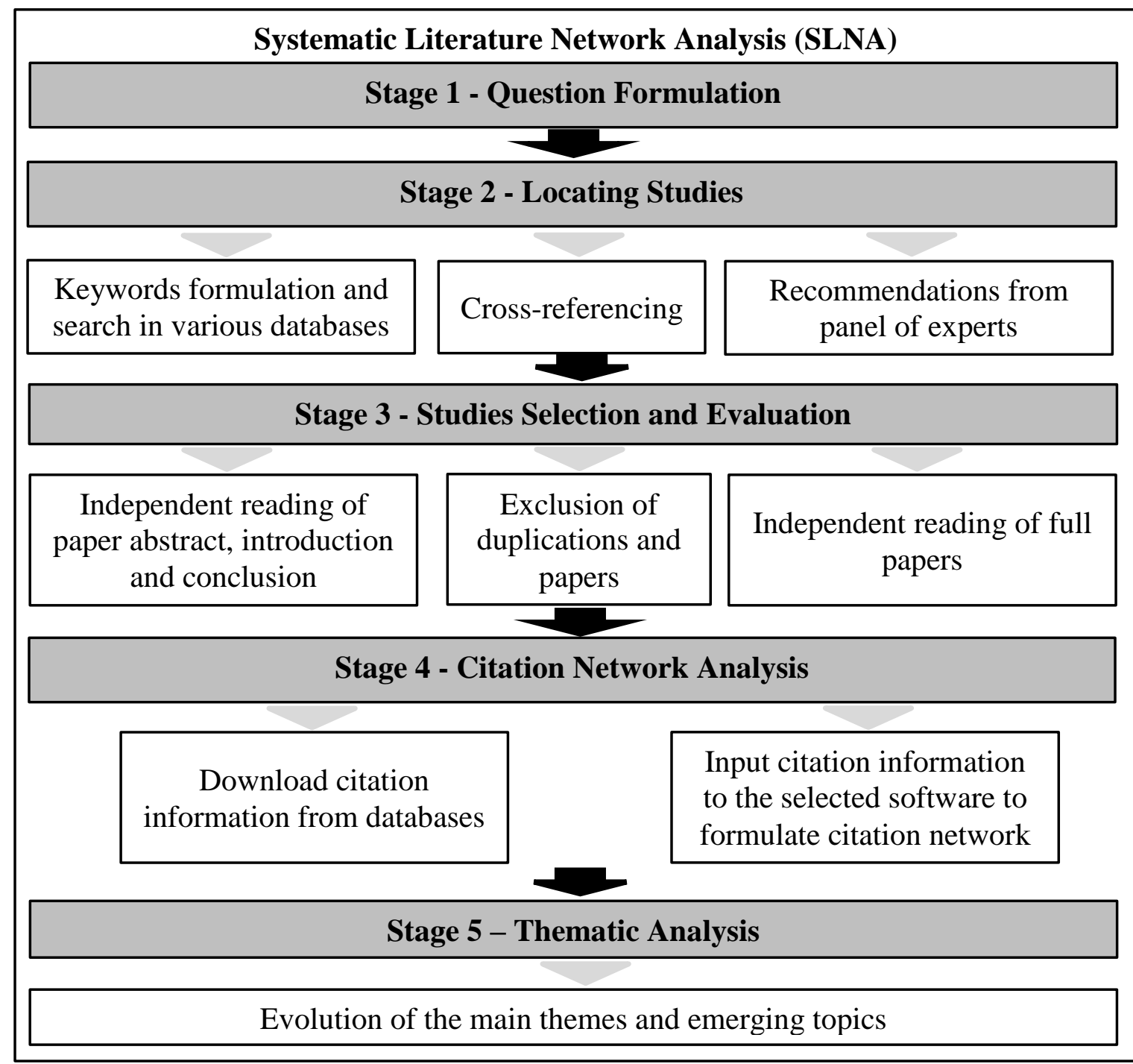

New Directions for Future Research 


\section{Appendix B. Search and selection process of the studies}

Initial search with the selected keywords in the selected databases resulted in 632 papers
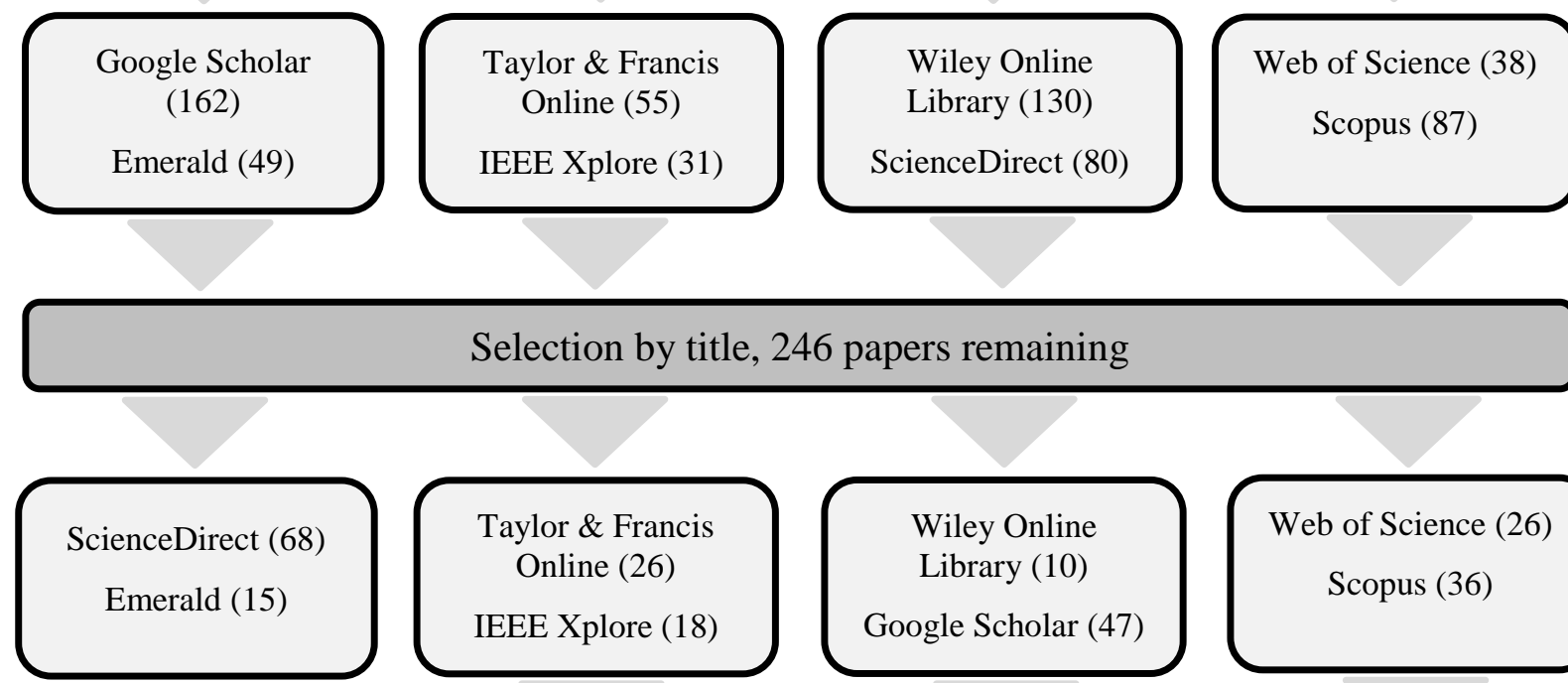

Taylor \& Francis Online (26)

IEEE Xplore (18)
Wiley Online

Library (10)

Google Scholar (47)
Web of Science (26)

Scopus (36)

\section{Duplication removal - 94 papers remaining}

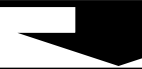

Selection by reading the abstract, introduction and conclusion - 82 papers remaining

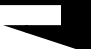

Selection by reading the full paper - 62 papers remaining

Cross reference analysis -9 papers were added to the analysis list

Finally, 71 papers were selected to do the citation network analysis 